\title{
Buying a Blind Eye: Campaign Donations, Regulatory Enforcement, and Deforestation in Colombia
}

\author{
Robin Harding Mounu Prem Nelson A. Ruiz David L. Vargas *
}

\begin{abstract}
While existing work has demonstrated that campaign donations can buy access to benefits such as favorable legislation and preferential contracting, we highlight another use of campaign contributions: buying reductions in regulatory enforcement. Specifically, we argue that in return for campaign contributions, Colombian mayors who rely on donor-funding (compared to those who do not) choose not to enforce sanctions against illegal deforestation activities. Using a regression discontinuity design, we show that deforestation is significantly higher in municipalities that elect donor-funded as opposed to self-funded politicians. Further analysis shows that only part of this effect can be explained by differences in contracting practices by donor-funded mayors. Instead, evidence of heterogeneity in the effects according to the presence of alternative formal and informal enforcement institutions, and analysis of fire clearance, support the interpretation that campaign contributions buy reductions in the enforcement of environmental regulations.
\end{abstract}

KEYWorDs: Campaign donations, Deforestation, Regulatory enforcement

\footnotetext{
${ }^{*}$ We thank Tatiana Mendoza, Camilo Ortega, and Mateo Uribe for helpful comments and suggestions. Harding: University of Oxford, Department of Politics and International Relations, email: robin.harding@politics.ox.ac.uk; Prem: School of Economics, Universidad del Rosario, e-mail: francisco.munoz@urosario.edu.co; Ruiz: University of Oxford, Department of Politics and International Relations, e-mail: nelson.ruiz@politics.ox.ac.uk and School of Economics, Universidad del Rosario; Vargas: Inter-American Development Bank, email: davidvar@iadb.org. Prem acknowledges IAST funding from the French National Research Agency (ANR) under the grant ANR-17-EURE-0010 (Investissements d'Avenir program). Opinions, findings, conclusions, and recommendations expressed here are those of the authors and do not necessarily reflect the views of the Inter-American Development Bank.
} 


\section{Introduction}

Between 2015 and 2018, tens of thousands of hectares of forest were destroyed in the Colombian municipalities of Calamar and Miraflores, with the rate of devastation tripling over the period. ${ }^{1}$ Clearance of the forest was connected in part to the development of a $138 \mathrm{~km}$ road, constructed between the two municipalities without the required environmental permits or licenses. Responsibility to enforce these environmental regulations lay with the mayors of the municipalities. But rather than enforce the laws, the mayors chose to turn a blind eye, allowing the illegal road construction and related deforestation to proceed. While some ordinary citizens may have appreciated the improved transportation links, the primary beneficiaries of this failure to enforce environmental regulations were local elites and cattle ranchers, looking to capitalise on the forest clearance for financial gain. Indeed, over this same period these two municipalities experienced high levels of vegetation fires, a common practice used by farmers to illegally clear lands for cattle ranching and illicit crop cultivation, and one which mayors also have a responsibility to monitor and prevent. ${ }^{2}$ We argue that, given the benefits to be had from forest clearance, campaign donations are used to buy regulatory non-enforcement of this type, as mayors choose not to sanction illegal deforestation in return for campaign contributions.

Previous research has provided evidence that campaign donations can be used to buy benefits such as favourable legislation and preferential access to contracting or public sector jobs (Stratmann, 2005; Boas, Hidalgo and Richardson, 2014; Ruiz, 2017; Colonnelli, Prem and Teso, 2020). But the case described above highlights another use of campaign contributions: buying regulatory nonenforcement. An important strand of the public choice literature has highlighted the phenomenon of state capture by economic elites, recognizing a variety of means by which a rich elite can gain disproportionate influence within a democracy, including through patronage, vote-buying, and lobbying (Acemoglu, Ticchi and Vindigni, 2011). Taking the use of campaign donations as another means by which economic elites can achieve state capture, we argue that donors to mayoral election campaigns in Colombia purchase reductions in the enforcement of environmental regulations.

We support this argument with evidence that mayors in Colombia allow violations of envi-

\footnotetext{
${ }^{1}$ See https://www.semana.com/nacion/articulo/trochas-ilegales-acaban-con-la-amazonia-colombiana/ 649428. Last accessed June 2021.

${ }^{2}$ See for example https://es.mongabay.com/2019/07/incendios-norte-amazonia-deforestacion-colombia/. Last accessed March 2022.
} 
ronmental regulations in return for campaign donations. Using a regression discontinuity design (RDD) on close elections between politicians who receive contributions from private donors and politicians that fund their own mayoral campaigns, we estimate that deforestation between 2012 and 2015 almost doubles in municipalities that elected a donor-funded mayor compared to those that elected a self-funded mayor. Given the central role of deforestation as a key driver of climate change, this is an important finding in itself. The quasi-experimental nature of the research design provides identification, overcoming concerns that differences in deforestation result, for example, from variation in pre-existing enforcement capacity or differences in other pre-term municipal characteristics. As such, although we do not observe variation in enforcement by local mayors directly, the research design allows us to infer that differences in deforestation result from donor-funded mayors pursuing a politically-motivated model of enforcement.

Given existing evidence on campaign donations and contracting, a possible alternative channel is that the estimated effect stems from an increase in infrastructure contracting rather than a reduction in regulatory enforcement. Analyzing the effects of victory by a donor-funded politician on contracting outcomes provides some support for this, because the average value of infrastructure contracts is larger under donor-funded mayors. However, temporal trends show that this channel can only explain part of the estimated increase in deforestation. Moreover, although infrastructure contracts that could increase deforestation primarily relate to roads, we see no evidence of an increase in road density following election of a donor-funded mayor. Further analysis supports the interpretation that campaign contributions buy reductions in the enforcement of environmental regulations.

First, we find that the effect of donor-funded mayors on deforestation is mitigated by the presence of alternative sources of environmental law enforcement. Specifically, exploring heterogeneous effects using pre-term municipal characteristics measuring the extent of protected National Parks (which are subject to higher central government monitoring than most forest areas), and the presence of and distance to offices of Colombia's regional environmental management institutions (Autonomous Regional Corporations, or CARs), we find that both dampen the effect of donorfunded mayors. Similarly, the effect is also attenuated by the number of offices of the Procurator General (Procuraduría) and the Attorney General (Fiscalía), which we take as additional proxies for the extent of state presence within a municipality. These results, therefore, suggest that tighter institutional oversight beyond that provided by mayors reduces the deforestation linked to 
the victory of a donor-funded politician.

Second, we find that the activities of illegal armed actors affect the deforestation dynamics linked to the election of a donor-funded politician. While guerrilla groups such as the Revolutionary Armed Forces of Colombia (FARC) have often obstructed and attacked the business of local elites, paramilitary groups arose out of private security forces created by large landowners and cattle ranchers, and frequently act to protect the interests of these local elites. Exploring heterogeneous effects using pre-term measures of attacks by armed groups, we find that while guerrilla attacks substantially lower the deforestation related to the victory of donor-funded politicians, attacks by paramilitary groups have no such impact. Third, unlike large-scale infrastructure projects, deforestation for cattle ranching and cultivation often makes use of aggressive and frequently illegal practices of clearance by burning. Using data from NASA's Fire Information for Resource Management System (FIRMS), we find a $32.9 \%$ increase in average fire intensity in donor-funded municipalities.

These results are consistent with donor-funded mayors selling regulatory non-enforcement. As explained in Section 3, Colombia's local elites have a long history of land appropriation and illegal expansion of the agricultural frontier. In line with existing arguments about local state capture by wealthy elites in Colombia and elsewhere (Sánchez-Talanquer, 2020; Hollenbach and Silva, 2019), our argument suggests that campaign donations create a connection between elites and the ruling mayor. This connection provides elites with a degree of protection when engaging in deforestation activities, as donor-funded mayors turn a blind eye to violations of environmental regulations.

The findings make at least three important contributions. First, they advance the literature on the influence of money in politics. Not only do campaign donations buy favourable legislation and access to preferential contracts, but they also buy the selective non-enforcement of laws. Second, in this way, the results also contribute to the literature on state capture. We provide evidence that campaign donations are used to purchase influence over the local state, which in this instance results in a reduction in regulatory enforcement. Third, the findings make an important contribution to our understanding of the political dynamics of deforestation. In doing so, they have the potential to inform the design of better policies to deal with the urgent challenge of climate change.

Existing work on the impact of corruption on environmental outcomes highlights the role of electoral incentives in ensuring the enforcement of environmental regulations (Aklin et al., 2014). 
This is in line with more general arguments about the ability of electoral accountability to generate effective enforcement and reduce the impact of corruption (Hurwicz, 2008; Olken and Pande, 2012). Yet, as Hurwicz (2008) notes, for elections to provide an effective means of "guarding the guardians" requires them to be free. The purchase of reduced regulatory enforcement through campaign donations by local elites subverts this process, highlighting the need to insulate enforcement, and its oversight, from distorted electoral incentives. This emphasises the importance of considering the complex interactions between interest groups, elected officials, and bureaucrats, in order to fully understand the politics of deforestation and natural resource management.

\section{Deforestation, donations, and state capture}

Deforestation. Increasing awareness of the threat posed by climate change has created an urgency in efforts to understand its drivers. One key factor is deforestation, which is closely linked with global warming. ${ }^{3}$ Forests capture up to $45 \%$ of terrestrial carbon and remove large amounts of carbon dioxide (Bonan, 2008). However, despite the importance of these ecosystems, they are being destroyed at alarming rates. ${ }^{4}$ Limiting deforestation is therefore vital in combating climate change, and accurately understanding the causes of deforestation is crucial to these efforts. Existing research has highlighted activities such as cattle ranching, farming, logging, and urbanisation as leading causes of deforestation (Curtis et al., 2018). Understanding factors influencing the intensity of these activities can therefore facilitate more suitable policy design to effectively manage deforestation (see, for example, Prem, Saavedra and Vargas, 2020).

One such factor is electoral competition, which has been argued to influence deforestation in contrasting ways. On one hand, the mere existence of democracy may limit deforestation. Li and Reuveny (2006) provide evidence that democratic regimes reduce deforestation, along with other forms of environmental degradation. This positive impact of democracy results from various mechanisms, including increased access to information about environmental problems, the greater role of public opinion in policy making, and the aggregation and representation of interest groups. Similarly, Gulzar, Lal and Pasquale (2021) find that local government representation in India substantially reduces deforestation. In contrast, Morjaria (2012) demonstrates that deforestation

\footnotetext{
${ }^{3}$ See https://www.nationalgeographic.com/environment/article/deforestation. Last accessed April 2021.

${ }^{4}$ See https://www.wri.org/insights/numbers-value-tropical-forests-climate-change-equation. Last accessed April 2021.
} 
increased following the introduction of multi-party elections in Kenya in 1992, as districts loyal to the central government were allowed increased access to forest land. Likewise, Sanford (2021) provides cross-national evidence that competitive elections are associated with increased deforestation, arguing that deforestation provides short-term, private benefits to voters that politicians exploit to win (re-)election.

Another factor influencing deforestation is corruption. Burgess et al. (2012) argue that the management of logging rules in Indonesia is driven by a process of rent maximisation by local officials. Focusing on Brazil, Pailler (2018) also highlights the role of corruption in encouraging deforestation. Connecting corruption back to electoral competition, she argues that corrupt politicians exploit forest resources to fund their re-election campaigns. This is supported with evidence from Brazilian municipalities demonstrating an increase in deforestation in election years, but only in municipalities where corrupt incumbent mayors are running for re-election. Unlike our argument, however, Pailler (2018) suggests the link between deforestation and campaign finance is due to activities such as granting licenses for firms to engage in deforestation-related activities, rather than a reduction in enforcement. In contrast, Balboni et al. (2021) find evidence of a decrease in forest fires in election years in Indonesia, followed by a steep increase the following year.

Campaign donations. Arguments about re-election incentives connect deforestation firmly to the literature on campaign contributions. It is well-established that campaign donations can buy preferential treatment in the form of favourable legislation or privileged access to contracts or licenses. Although studies have provided mixed evidence concerning the impact of campaign contributions on policy decisions, a meta-analysis by Stratmann (2005) supports the claim that contributions do affect legislative voting behaviour. This is consistent with theoretical models which hypothesise that politicians will grant policy favours in exchange for campaign donations. ${ }^{5}$

Moreover, recent evidence has demonstrated clear effects of campaign donations on preferential access to government contracts. Using an RDD to analyse data from Brazil, Boas, Hidalgo and Richardson (2014) find that firms specialising in public-works projects receive a substantial boost in contracts when they donate to a ruling party candidate who wins the election. Similarly, Ruiz (2017) shows that electing a donor-funded politician more than doubles the probability of donors receiving contracts in Colombia. Linking donations and deforestation more closely, Bulte, Damania

\footnotetext{
${ }^{5}$ For examples see: Snyder (1990); Austen-Smith and Wright (1994).
} 
and Lopez (2007) found that wealthy Latin-American farmers bribe politicians with contributions to obtain rural subsidies that are associated with low land productivity and excessive deforestation.

State capture. Tying this literature together, we argue that campaign donations can influence deforestation through an alternative channel: by purchasing reductions in the enforcement of environmental regulations. In this way, campaign donations serve to achieve a form of local state capture, whereby a rich elite exert excessive influence over the local state. Existing literature has highlighted a variety of means by which economic elites gain disproportionate influence within a democracy, including through patronage, vote-buying, and lobbying. For example, Acemoglu, Ticchi and Vindigni (2011) present a model in which the rich generate an inefficient state structure by co-opting bureaucrats through patronage. This allows the rich to capture democratic politics, thereby reducing the amount of redistribution under democracy.

Other studies offer clear examples of state capture in practice. Hollenbach and Silva (2019) provide evidence from Brazil that wealthy elites corrupt local officials and undermine state fiscal capacity to lower their own tax liabilities. Similarly, Sánchez-Talanquer (2020) argues that local elites in Colombia used their influence over mayors to keep land undervalued, thereby limiting their tax burdens. Both cases highlight the use of economic power by wealthy elites to exert disproportionate influence over the local state, to their own benefit. We make a similar argument, that local elites in Colombia use their economic influence to achieve local state capture. By our account, however, this influence is asserted through campaign donations, in return for which donorfunded mayors reduce the enforcement of environmental regulations. ${ }^{6}$

As we discuss in Section 3, local elites in Colombia have strong economic interests in activities such as cattle ranching and cultivation that represent a significant threat to forests. The pursuance of these interests is limited by environmental regulations designed to restrict deforestation, which municipal authorities have a responsibility to enforce. Mayors therefore have the power, as the heads of municipal authorities, to reduce the extent of regulatory enforcement, to benefit local elites. We argue that they do so in return for campaign donations that fund their election to office.

\footnotetext{
${ }^{6}$ This argument resonates with the literature on forbearance, or the selective non-enforcement of laws for political ends. A major contribution of recent work on forbearance has been to demonstrate its political use as a form of redistribution to win votes from the poor (Holland, 2017). Within that work, there is also an acknowledgement that forbearance can take more regressive forms, benefiting individuals at the upper end of the income distribution (Holland, 2016). As such, our findings may be taken as evidence of this type of 'forbearance as corruption'.
} 


\section{Context}

Deforestation in Colombia. Natural forest covers between half to two-thirds of Colombia's surface area, an amount that includes about $10 \%$ of the Amazon rainforest. ${ }^{7}$ Part of this forest, equivalent to $17 \%$ of the country, is designated as a protected area under the care of the National Parks administration, and is subject to more stringent regulation and monitoring overseen directly by the national government. ${ }^{8}$ Yet as elsewhere in the world, deforestation is an increasing problem. From 2001 to 2020, Colombia lost more than 4.6 million hectares of tree cover, equivalent to a $5.7 \%$ decrease in the total forest area (Global Forest Watch, 2019).

As in much of Latin America, the most notorious driver of deforestation is cattle ranching (FAO, 2006). Colombia has a long history of cattle production, being the fourth largest cattle breeder in the region and the seventh worldwide, and over 200 thousand hectares of forest are lost each year to pasturing. ${ }^{9}$ The impact of cattle ranching on deforestation has been accompanied by the deleterious effects of other activities such as mining, illegal logging and crop production, infrastructure development, and the growth of agro-businesses.

Deforestation in Colombia has also been affected by the country's shifting political environment. Following the December 2014 ceasefire, and the FARC's subsequent disarmament in 2016, deforestation rose in areas previously under FARC control (Prem, Saavedra and Vargas, 2020). That this effect was greater in areas with lower state presence and more land-intensive economic activities highlights the impact of regulatory enforcement and activities such as cattle ranching on deforestation.

Economic interests of local elites. Land-intensive activities of this type are key to the economic interests of Colombian local elites. Since colonial times, Colombian landlords have steadily increased their land ownership and consolidated their power through it (Fernandez, 2012; LeGrand, 1988), resulting in substantial land inequality. This inequality has been exacerbated by violent periods such as 'La Violencia' in the late-1940s, which led to massive forced displacement and land expropriation (Guzmán, Fals Borda and Umaña, 2010; Fernandez, 2012). Moreover, institutional efforts to alter the distribution of land have been instrumentalised by elites to appropriate large land extensions

\footnotetext{
${ }^{7}$ Global Forest Watch (2019), IDEAM webpage (last accessed March 2022).

${ }^{8}$ See https://news.mongabay.com/2021/03/colombias-national-parks-at-a-crossroads-as-new-director -installed/. Last accessed June 2021.

${ }^{9}$ For details on the cattle industry in Colombia, see UNODC (2016).
} 
(Ibañez and Muñoz-Mora, 2010).

Land inequality is a factor underpinning the presence of illegal armed actors in Colombia. The foundation of guerrilla groups such as the FARC was justified in part to protect impoverished rural people, and as such these groups presented themselves as enemies of the local elites. In response, the rise of guerrilla groups led to the creation of private security forces used by wealthy landowners and cattle ranchers. These forces represented the precursors to far-right paramilitary groups, which frequently act to protect and promote the interests of local elites. ${ }^{10}$ Central to these interests are activities involving intensive land exploitation, such as ranching and cultivation, which are key drivers of deforestation.

Environmental regulatory institutions. Colombia's National Environmental System (Sistema Nacional Ambiental, SINA) governs the implementation of a set of general environmental principles. ${ }^{11}$ Under SINA, the Ministry of Environment leads and coordinates environmental management, but the key institutional actors responsible for implementing environmental policy are the CARs. As independent corporate entities endowed with fiscal and administrative autonomy, CARs have broad responsibility for managing natural resources and promoting sustainable development within their territories. This remit includes granting required environmental concessions, permits, or licences, overseeing activities involving natural resources, collecting fees and tariffs for the use of renewable resources, and imposing sanctions when environmental protection norms are violated.

Despite the CARs' jurisdiction over the nation's natural resources, their ability to maintain oversight and enforce regulations is often insufficient (Montes Cortés, 2018). Hence, other institutional actors also play a significant role in environmental protection. The national government, through the Ministry of Environment, the Department of Planning, and the army, contribute to protecting Colombia's natural habitat. Moreover, local governments at both the department and municipality levels are legally required to support CARs and implement national environmental policy within their territories.

Under the Constitution, mayors represent the foremost policing authorities within their municipalities, and are responsible for supervising the National Police assigned to the area under their

\footnotetext{
${ }^{10}$ See https://es.insightcrime.org/investigaciones/elites-crimen-organizado-colombia-introduccion/. Last accessed April 2021.

${ }^{11}$ See https://www.minambiente.gov.co/ordenamiento-ambiental-territorial-y-sistema-nacional -ambiental-sina/. Last accessed February 2022. For information on environmental regulatory institutions in Colombia see Blackman, Morgenstern and Topping (2006).
} 
jurisdiction. This includes the specialized Environmental and Natural Resource Police unit created to assist territorial authorities with the enforcement of environmental laws. ${ }^{12}$ Furthermore, municipal governments have various legal mechanisms to enforce environmental laws, including the imposition of sanctions, suspension of environmental licenses, permits, or concessions, and power to close or demolish businesses and seize products or equipment. Therefore, mayors have significant responsibilities for enforcing environmental regulations, and have substantial powers to meet these responsibilities.

Colombian Local Elections. Since 1986, mayors in Colombia have been directly elected via a first-past-the-post system for a single four-year term. ${ }^{13}$ The mayor's term coincides exactly with the calendar year. For the period we study, the mayoral term starts January 1, 2012 and ends December 31, 2015. Colombian mayoral election campaigns are expensive. For the 2015 municipal elections, the total spent on mayoral campaigns was more than 238 billion pesos (about 82 million US dollars), equivalent to $71 \%$ of the nation's entire science and technology budget (MOE, 2018). Despite this cost, public resources available for local election campaigns are scarce, and campaigns are primarily financed by personal resources and private donations (Casas-Zamora and Falguera, 2016). Furthermore, campaigns are frequently highly competitive, and there is a strong correlation between campaign spending and the probability of victory (Gulzar, Robinson and Ruiz, 2020). Consequently, candidates have powerful incentives to secure private contributions. Such campaign contributions can be very valuable to donors, with the election of a donor-funded politician increasing the probability that donors receive municipal contracts (Ruiz, 2017).

As discussed in Ruiz (2017), mayors in Colombia have discretion over around $20 \%$ of spending within their municipalities, with resources from property tax revenues funding services including education, healthcare, water, and sanitation. Some of the activities undertaken under the purview of these contracts, especially where they involve infrastructure provision such as road construction, are likely to result in deforestation and other forms of environmental degradation. ${ }^{14}$ We explore this empirically in Section 6. But given the strong economic interest that local elites have in land-intensive activities such as forest clearance and cattle ranching, and the crucial role that

\footnotetext{
${ }^{12}$ Mayors also have a duty to procure sufficient resources for fire services within their municipalities, in part to stop forest fires from expanding and mitigate illegal deforestation. See https://www.procuraduria.gov.co/portal/ Procuradora-apropiacion-recursos-servicio-bomberos.news. Last accessed June 2021.

${ }^{13}$ Mayors cannot serve consecutive terms, but can be reelected to non-consecutive terms.

${ }^{14}$ Examples of such contracts in the data that we employ include works to the road connecting the municipality of Regidor with the township of San Cayetano, and the improvement of rural roads in San Jose del Guaviare.
} 
mayors play in the enforcement of environmental regulations limiting such activities, our central argument is that campaign donations also purchase reductions in regulatory enforcement. In return for campaign contributions, mayors turn a blind eye to the illegal exploitation of land, thereby facilitating deforestation.

\section{Data}

Combining data from various sources we build a municipality-candidate level dataset to study the effect of a donor-funded politician victory on deforestation. We focus on the 2011 elections and the subsequent 2012-2015 mayoral term.

Election results and campaign donations. Electoral information comes originally from Pachón and Sánchez (2014), who gathered mayoral election results for all municipalities reported by the Registraduría Nacional del Estado Civil, the Colombian electoral authority. Campaign contributions data was collected from the National Electoral Commission by Ruiz (2017), who shows it to be highly reliable with low incentives to misreport. Political parties were obliged to electronically report sources and amounts of campaign expenditure, and then provide physical evidence corroborating this. Moreover, in 2011 the Electoral Commission had the power to penalize candidates with fines, which generated an $89 \%$ compliance rate (Ruiz, 2017). The commission subsequently lost this sanctioning power, limiting reporting compliance for the 2015 electoral period, and therefore we focus our analysis on the 2011 elections. ${ }^{15}$

We code candidates as donor-funded if they receive any private donations. Results in the appendix show the findings are robust to various alternative definitions setting thresholds on the share of private funding and the number of private donors and donations (Appendix Table A1). Of the 1,080 municipalities that elected mayors in 2011, our sample is first restricted to the 996 municipalities where the top two candidates reported their campaign financing. Of these, we focus on the 408 races decided between a candidate who received private donations and one who did not, implementing an RDD around the margin of victory of the candidates. These races are arguably representative; they are spread throughout the country, and across a variety of characteristics the municipalities in the sample are not statistically different to those that are excluded (Appendix

\footnotetext{
${ }^{15}$ No data on campaign donations is available for elections prior to 2011 because the reporting system was introduced in 2009.
} 
Table A2).

Deforestation. Our measurement of deforestation comes from the Global Forest Change dataset collected by Hansen et al. (2013), who analyse Landsat satellite images to identify changes in forest cover between 2000-2020. These data, comprising pixels of 30 meters by 30 meters (approximately), have been widely used to measure deforestation (Prem, Saavedra and Vargas, 2020; Zhu et al., 2016).

Tree cover is defined as vegetation taller than 5 meters and is coded as a percentage per output grid cell. We adopt a definition that considers any pixel with tree cover superior to $50 \%$ of its surface as forest. Hence, deforestation is a pixel change from the status of forest to non-forest. This data is aggregated to the municipal level. Using the baseline coverage levels and the yearly tree-cover loss and gain for each municipality, we recover the yearly coverage in each municipality, allowing us to calculate our deforestation measure. ${ }^{16}$ Our primary deforestation variable is defined as the negative of the change in forest area in the municipality during the mayor's term relative to the municipality tree cover in the year before the new mayor's mandate, as follows:

$$
\text { (Relative) Deforestation in term }=\frac{-\Delta \text { Coverage }_{\text {government term }}}{\text { Coverage }_{\text {election year }}} .
$$

We calculate the deforestation measure for the 2011 election (2012-2015 government term) and the previous election, the 2007 election (2008-2011 government term). ${ }^{17}$ Figure 1 shows that deforestation was a broad phenomenon across the country during the study period. Moreover, deforestation was rapidly consuming the country's tree cover. As shown in Table 1, the 1,080 municipalities that elected a mayor in 2011 lost on average almost 1.2\% of their tree-cover during the subsequent mayoral term (2012-2015).

Additional data. Since illegal deforestation is often undertaken using aggressive fire clearance, we use FIRMS data to track fires during the study period. ${ }^{18}$ We use detailed contracting data from the SECOP system, which collects information on all government contracts, to investigate whether the estimated effect of donor-funded candidate victory results from an increase in deforestation-related

\footnotetext{
${ }^{16}$ The yearly coverage is obtained as coverage $t=$ coverage $_{2000}+\sum_{i=2001}^{t}\left(\right.$ gain $_{i}-$ loss $\left._{i}\right)$.

${ }^{17}$ The main results are robust to an alternative deforestation measure calculated relative to the year 2000 . These results are available upon request.

${ }^{18}$ We acknowledge the use of data and/or imagery from NASA's Fire Information for Resource Management System (FIRMS) (https://earthdata.nasa.gov/firms).
} 


\section{Figure 1: Deforestation during term by municipality}

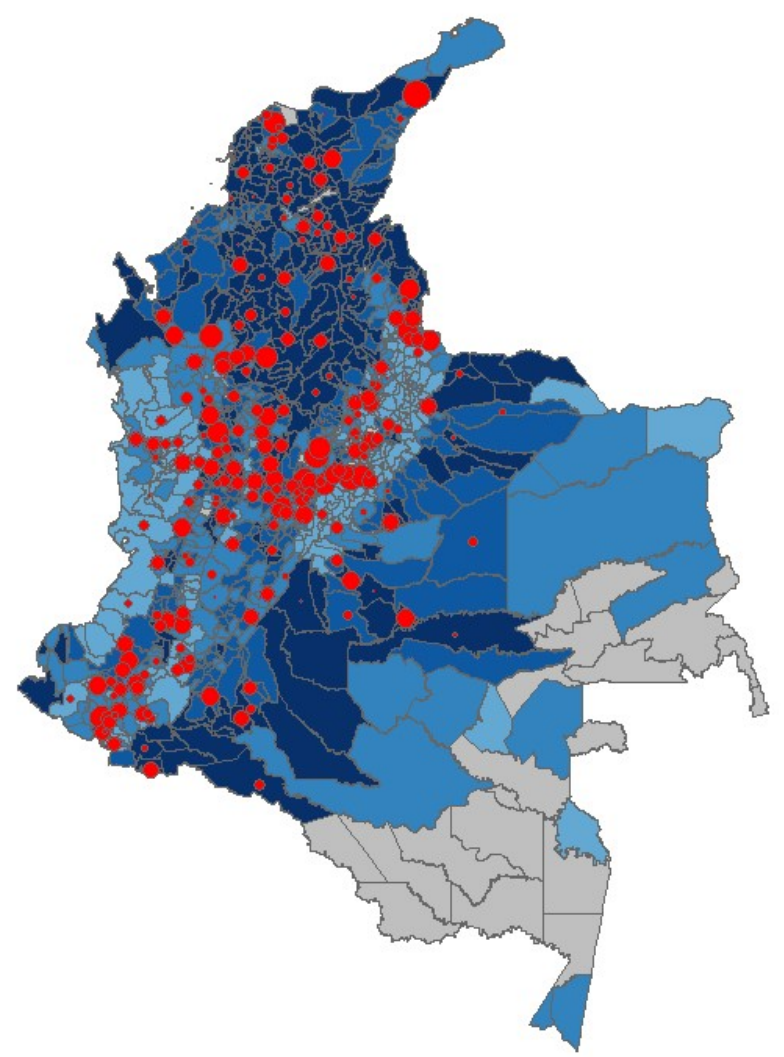

Note: This figure shows the geographical distribution of deforestation and the vote share of privately funded candidates for the 2011 election period. The shades of blue correspond to the quartiles of deforestation during the full term. The bubble size correspond to the quartiles of the margin of victory privately funded candidates.

Table 1: Summary statistics

\begin{tabular}{|c|c|c|c|c|c|c|}
\hline & (1) & $(2)$ & $(3)$ & $(4)$ & $(5)$ & $(6)$ \\
\hline & Obs & Mean & $\begin{array}{l}\text { Standard } \\
\text { Deviation }\end{array}$ & Minimum & Median & Maximum \\
\hline \multicolumn{7}{|l|}{ A. Elections } \\
\hline Private income $\%$ total & 2160 & 0.19 & 0.27 & 0 & 0 & 1 \\
\hline Margin of victory donor-funded & 408 & 0.022 & 0.101 & -0.354 & 0.019 & 0.383 \\
\hline \multicolumn{7}{|l|}{ B. Deforestation } \\
\hline Deforestation ratio $2008-2011$ & 1080 & 2.141 & 2.023 & 0 & 1.526 & 14.565 \\
\hline Deforestation ratio 2012-2015 & 1080 & 1.182 & 1.572 & 0 & 0.576 & 16.625 \\
\hline
\end{tabular}

Note: This table presents summary statistics for the main variables of interest used in the analysis. An observation is a municipality except for the Private income \% total that uses as unit of observation the candidate (top two candidates per each municipality). 
contracting. To evaluate whether the main effects are mediated by the presence of illegal armed groups we use the violent events data collected by Restrepo, Spagat and Vargas (2004) and updated by Universidad del Rosario. ${ }^{19}$ Finally, we use a set of municipal-level covariates taken primarily from data collected by Universidad de Los Andes and their Center For Economic Development Studies.

\section{Empirical Strategy}

If campaign donations purchase reductions in the enforcement of environmental regulations designed to limit deforestation, we should expect to see more deforestation in municipalities electing donorfunded mayors. However, the victory of a donor-funded candidate is plausibly correlated with a broad range of municipal characteristics, including enforcement capacity. Moreover, deforestation itself may be determined by municipality characteristics. For example, more rural municipalities might have more cattle ranching that may increase deforestation. Due to these identification problems, a straightforward comparison of deforestation across municipalities electing donor-funded as opposed to self-funded mayors may be confounded by local municipality characteristics.

To overcome these problems, we employ a quasi-experimental Regression Discontinuity Design (RDD). Using the margin of victory as the running variable, we take advantage of the discontinuous change at the threshold between victory of a donor-funded as opposed to a non-donor-funded mayor. This defines the treatment rule:

$$
L_{i}= \begin{cases}L_{i}=1 & \text { if } x_{i}>0 \\ L_{i}=0 & \text { if } x_{i}<0\end{cases}
$$

where $x_{i}$ reflects margin of victory for the donor-funded politician, and $L_{i}$ represents treatment status, as a dummy variable taking the value of one if a donor-funded politician won the election.

Following this, our main analysis estimates a regression of the form:

$$
y_{i}=\alpha+\beta_{1} L_{i}+\beta_{2} f\left(x_{i}\right)+\beta_{3} L_{i} \times f\left(x_{i}\right)+\varepsilon_{i}
$$

\footnotetext{
${ }^{19}$ For details see Prem et al. (2022).
} 
Here $y_{i}$ is the outcome, measured as the change in deforestation during the elected mayor's term in office. $\beta_{1}$ is our estimate of the effect of electing a donor-funded mayor. $f\left(x_{i}\right)$ is a polynomial in the donor-funded politician margin of victory. Finally, $\varepsilon_{i}$ corresponds to the idiosyncratic error term.

Correctly estimating $\beta_{1}$ requires two key assumptions: (1) there should be no manipulation of election results around the cut-off, and (2) covariates potentially correlated with the treatment and outcome variables must vary smoothly around the cut-off. On the first, results from the Cattaneo, Jansson and Ma (2018) manipulation test based on density discontinuity presented in Figure 2 show no statistically significant evidence of systematic manipulation. ${ }^{20}$ On the second, Table 2 shows there is no discontinuity of covariates at the cut-off, suggesting that municipalities are similar except in the treatment status.

\section{Figure 2: Manipulation Test}

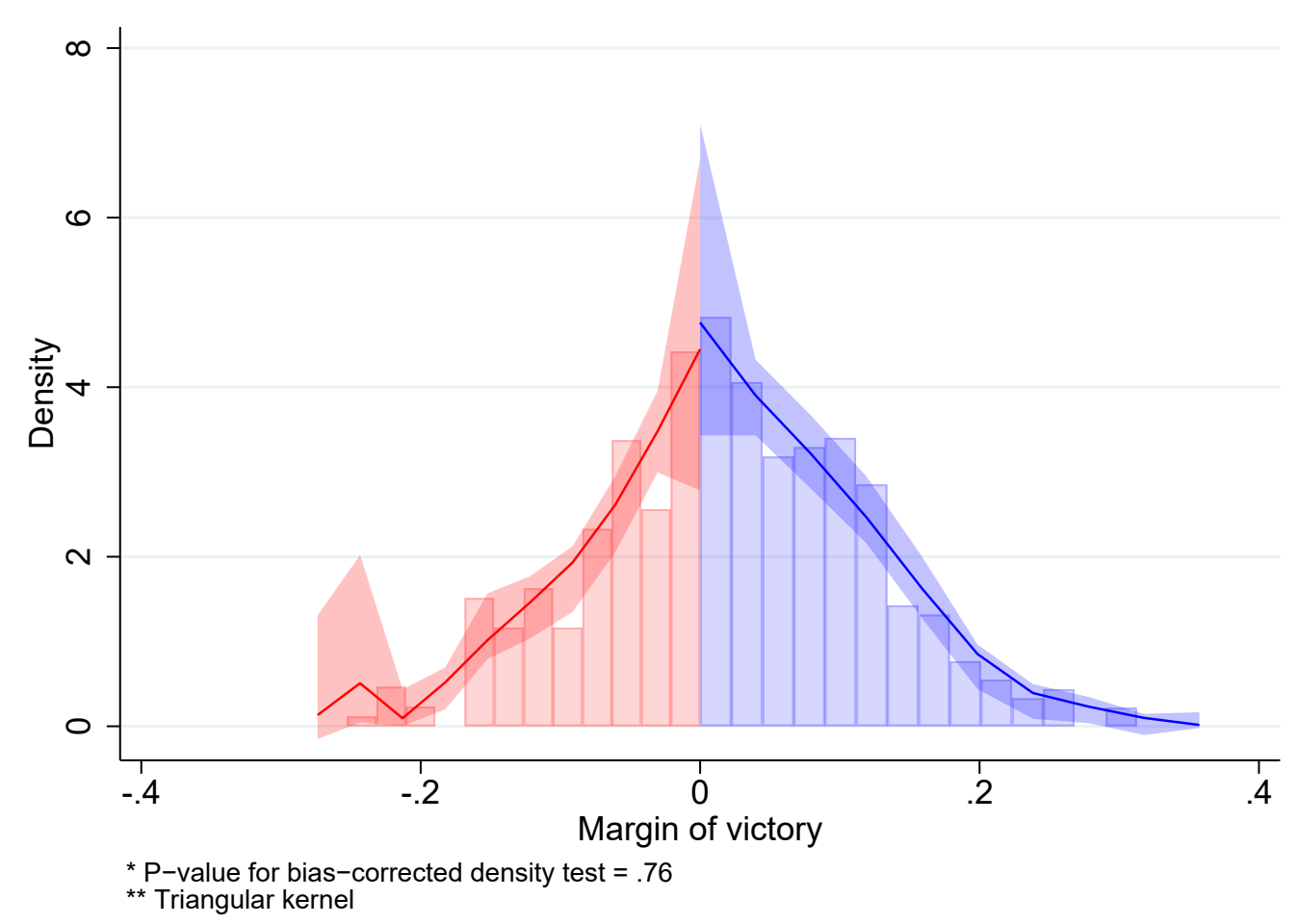

Note: This figure presents the density test suggested by Cattaneo, Jansson and Ma (2018) using a quadratic polynomial and triangular kernel weights. The p-value for the bias corrected density test is 0.76 . The p-values using a polynomial of degree one and three are 0.25 and 0.59 , respectively.

\footnotetext{
${ }^{20}$ Similar results are found using the McCrary (2008) test for sorting around the threshold with a p-value of 0.29.
} 
Table 2: Smooth covariates

\begin{tabular}{|c|c|c|c|c|c|c|c|}
\hline & $\begin{array}{c}(1) \\
\text { Mean }\end{array}$ & $\begin{array}{c}(2) \\
\text { Std. Dev. }\end{array}$ & $\begin{array}{c}(3) \\
\text { Donor fund. won }\end{array}$ & Std. Error. & $\begin{array}{l}(5) \\
\text { Obs }\end{array}$ & $\begin{array}{c}(6) \\
\text { P-value }\end{array}$ & $\begin{array}{c}(7) \\
\text { Pval Canay }\end{array}$ \\
\hline \multicolumn{8}{|l|}{ Panel A: Individual covariates } \\
\hline Women & 0.116 & 0.320 & 0.119 & 0.202 & 132 & 0.121 & 0.789 \\
\hline Age & 45.245 & 9.709 & -3.551 & 5.398 & 126 & 0.573 & 0.061 \\
\hline Black & 0.044 & 0.205 & -0.023 & 0.195 & 126 & 0.865 & 0.490 \\
\hline Indigenous Background & 0.107 & 0.309 & 0.050 & 0.230 & 126 & 0.570 & 0.423 \\
\hline Left-wing party & 0.024 & 0.154 & 0.018 & 0.165 & 132 & 0.801 & 0.664 \\
\hline Right-wing party & 0.239 & 0.427 & 0.181 & 0.147 & 132 & 0.474 & 0.816 \\
\hline Illegal Registration of ID. & 0.005 & 0.071 & 0.013 & 0.009 & 132 & 0.268 & 1.000 \\
\hline Has political experience & 0.361 & 0.480 & 0.156 & 0.181 & 132 & 0.336 & 0.871 \\
\hline \multicolumn{8}{|l|}{ Panel B. Policy Outcomes } \\
\hline Total Income Y(COP M) & 47102.906 & 361239.511 & 12723.550 & 8666.063 & 132 & 0.704 & 0.467 \\
\hline Land Taxes (\%Y) & 3.889 & 4.695 & 0.346 & 2.083 & 132 & 0.938 & 0.303 \\
\hline Industry $(\% \mathrm{Y})$ & 3.377 & 5.967 & 1.378 & 1.755 & 132 & 0.823 & 0.252 \\
\hline Funct. expen. (\%Y) & 13.284 & 5.045 & -1.439 & 4.719 & 132 & 0.535 & 0.758 \\
\hline Investment $(\% \mathrm{Y})$ & 86.716 & 5.045 & 1.439 & 4.719 & 132 & 0.535 & 0.757 \\
\hline Deficit $(\% \mathrm{Y})$ & 11.346 & 9.573 & 1.049 & 6.648 & 132 & 0.613 & 0.963 \\
\hline \multicolumn{8}{|c|}{ Panel C. Other municipality socio-economic characteristics } \\
\hline Altitude (meter) & 1158.170 & 1161.175 & -227.936 & 571.983 & 132 & 0.885 & 0.164 \\
\hline Area in Square km & 876.992 & 2982.007 & -91.459 & 578.174 & 132 & 0.323 & 0.713 \\
\hline Forest coverage (10 000 hectares) & 5.343 & 21.979 & -0.441 & 5.031 & 132 & 0.307 & 0.492 \\
\hline Proportion of forest coverage & 0.507 & 0.278 & -0.096 & 0.173 & 132 & 0.326 & 0.337 \\
\hline Agricultural land (10 000 hectares) & 3.803 & 11.146 & -0.017 & 3.132 & 132 & 0.921 & 0.769 \\
\hline Agricultural production (1000 ton) & 41.181 & 173.422 & 12.826 & 20.576 & 132 & 0.836 & 0.473 \\
\hline Distance to department capital & 78.701 & 56.010 & 13.930 & 25.906 & 132 & 0.855 & 0.112 \\
\hline Distance to Bogota & 319.459 & 189.400 & -84.390 & 183.531 & 132 & 0.286 & 0.609 \\
\hline Pop. density & 148.146 & 675.196 & 15.406 & 45.587 & 132 & 0.764 & 0.283 \\
\hline Road density & 0.829 & 0.451 & 0.256 & 0.250 & 132 & 0.356 & 0.252 \\
\hline Nighttime lights & 1.509 & 1.158 & 0.183 & 0.642 & 132 & 0.968 & 0.800 \\
\hline Literacy rate & 83.903 & 8.484 & -0.536 & 5.141 & 132 & 0.818 & 0.138 \\
\hline Rurality index $(0-1)$ & 0.564 & 0.239 & -0.107 & 0.133 & 132 & 0.322 & 0.225 \\
\hline Unsatisfied basic needs & 44.622 & 20.279 & 9.368 & 9.454 & 132 & 0.197 & 0.187 \\
\hline National Parks Area (10 000 sq. hectares) & 0.920 & 7.605 & 0.961 & 1.207 & 132 & 0.819 & 0.615 \\
\hline CAR office & 0.140 & 0.347 & -0.030 & 0.205 & 132 & 0.545 & 1.000 \\
\hline Distance to CAR office & 0.030 & 0.033 & -0.004 & 0.015 & 132 & 0.363 & 0.935 \\
\hline Procurator general offices & 0.604 & 6.388 & 0.044 & 0.091 & 132 & 0.636 & 1.000 \\
\hline Attorney general offices & 4.042 & 38.057 & 0.810 & 0.683 & 132 & 0.629 & 0.570 \\
\hline Paramilitary attacks & 1.279 & 9.780 & 0.151 & 1.882 & 132 & 0.724 & 0.173 \\
\hline Guerilla attacks & 0.608 & 2.091 & 0.424 & 1.215 & 132 & 0.995 & 0.205 \\
\hline \multicolumn{8}{|l|}{ Panel D. Other potential explanations } \\
\hline Deforestation during previous term & 2.141 & 2.019 & 0.685 & 0.641 & 132 & 0.334 & 0.365 \\
\hline Disposable Income (mw) & 29004.315 & 393732.953 & 1078.397 & 5317.036 & 126 & 0.719 & 0.305 \\
\hline Municipal category & 5.708 & 0.995 & 0.095 & 0.241 & 132 & 0.264 & 1.000 \\
\hline Mayor wages & 6.692 & 2.543 & -0.190 & 0.481 & 132 & 0.264 & 1.000 \\
\hline Council size & 10.957 & 2.907 & 1.775 & 1.292 & 132 & 0.217 & 0.081 \\
\hline Total population & 41707.711 & 257110.752 & 8672.028 & 9205.110 & 132 & 0.926 & 0.214 \\
\hline Income from royalties & 0.070 & 0.150 & 0.022 & 0.159 & 130 & 0.487 & 0.747 \\
\hline
\end{tabular}

Note: The first two columns present the basic statistics (mean and standard deviation) of each covariate. Column (3) reports the RDD's point estimate of the effect of a donor-funded candidate victory on each covariate (as dependant variable), the MSE optimal bandwidth for the main model is used throughout. Bias corrected robust standard errors (column 4). The number of effective observations is detailed in column 5. Column 6 reports the estimated p-value, while column 7 reports the Canay and Kamat (2018) permutation test for the null hypothesis of continuity of the distribution around the cutoff.

We follow Cattaneo, Idrobo and Titiunik (2020) and estimate the RDD specified in equation (3) non-parametrically using polynomials of order one and two, and weight observations accord- 
ing to their distance to the cutoff using triangular kernel weights. ${ }^{21}$ Additionally, we employ an optimal data-driven bandwidth selection procedure that minimises the asymptotic mean square error (MSE). Since MSE bandwidths produce non-robust confidence intervals, we estimate robust standard errors and confidence intervals but report conventional point estimates within the MSE optimal bandwidth (Cattaneo, Idrobo and Titiunik, 2020).

In further exercises, we perform parametric estimations, including additional interactions, to capture possible heterogeneous effects. In these, we estimate the RDD parametrically within the MSE optimal bandwidth sample, using OLS regression weighted by a triangular kernel, and controlling for a linear polynomial.

\section{Results}

\subsection{Main effects}

Figure 3 presents our main estimate of the effect of electing a donor-funded mayor on deforestation. The left and right panels show estimates using linear and quadratic polynomial approximations, respectively. We find a clear discontinuous jump in deforestation around the threshold determining victory of a donor-funded mayor. Moreover, the jump is statistically significant for both the linear and quadratic approaches. This result implies that the amount of deforestation in a municipality during a donor-funded mayor's term in office is significantly higher than that during the term of a self-funded mayor.

Table 3 presents the main result in greater detail. Our coefficient of interest represents the effect on deforestation of electing a donor-funded compared to a self-funded mayor. The estimates in Columns 2 and 4 also include the measure of deforestation for the previous term, 2008-2011. Prior deforestation varies smoothly around the cutoff, as shown in the lower panels of Figure 3, but we employ this measure as a robustness check and improve the precision of the estimates (Lee and Lemieux, 2010). The estimates are positive and significant across all specifications, showing robustness to linear or quadratic polynomials, and the inclusion of the previous deforestation measure. Moreover, the effect of electing a donor-funded politician is substantial, representing an increase in

\footnotetext{
${ }^{21}$ Appendix Table A3 presents results using a cubic polynomial.
} 


\section{Figure 3: Effect of electing a donor funded politician on deforestation}

\section{Panel A: Deforestation during the incumbency term}
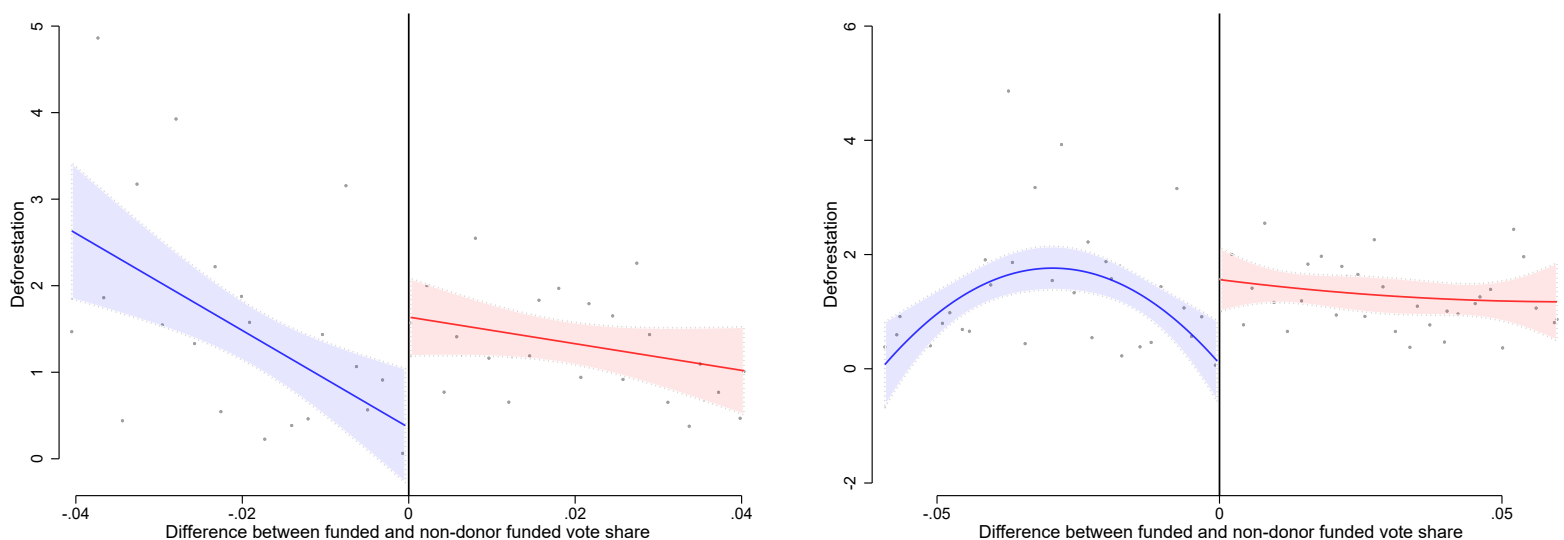

Panel B: Deforestation during the previous incumbency term
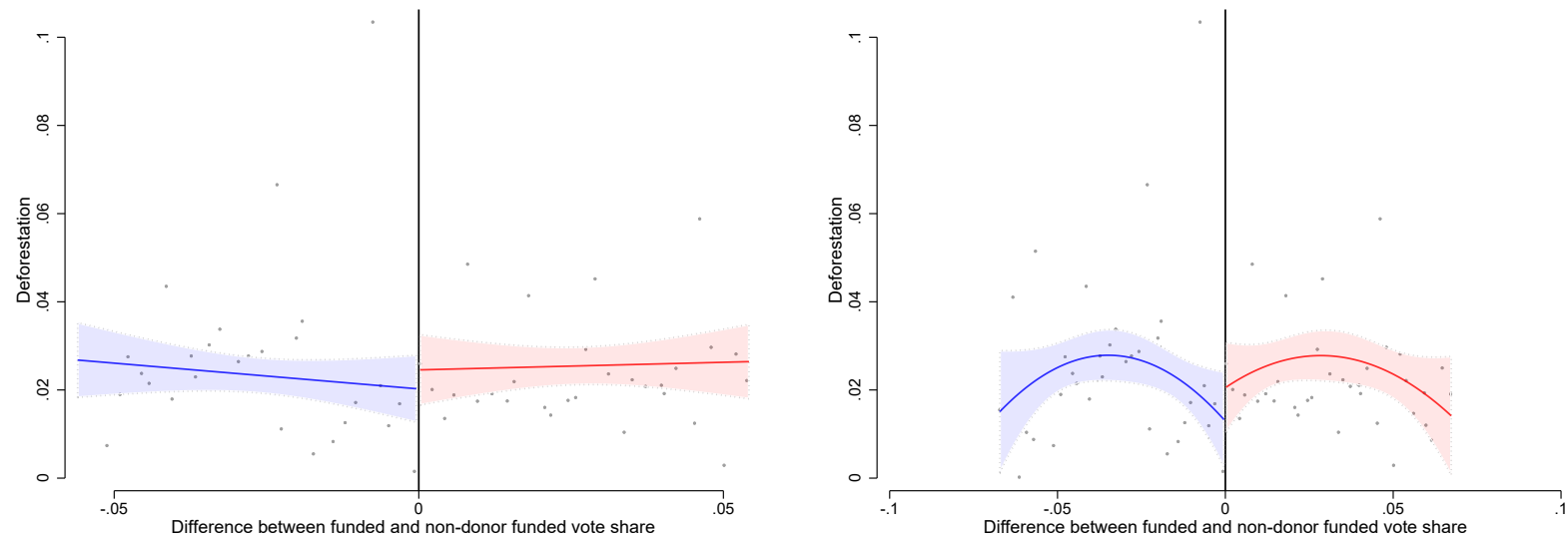

Note: This figure presents a graphical approximation of the regression discontinuity design. We present deforestation during the full incumbency term in the first row, while deforestation during the previous incumbency term is shown in the second row. The observations are shown within MSE optimal bandwidth. From left to right; the first figure uses a linear polynomial approximation, meanwhile, the second uses a quadratic approximation.

deforestation of $92.9 \%$ of the self-funded average for the linear specification. The effect size remains reasonably stable across specifications, ranging between $53 \%$ and $109 \%$ of the self-funded average.

In Figure 4, we explore the resilience of the results to variation in bandwidth size. Following best practice, we report results for a range of bandwidths around the MSE optimal bandwidth, from half to double the size. Overall the results are encouraging, with the effect remaining robust to a considerable range of bandwidths. It is not surprising that the results do not hold for very small bandwidths, for which the estimates are unlikely to have sufficient power. However, the effect remains reassuringly robust up to bandwidths of 0.08 , where races are far less competitive and municipalities less comparable. 
Table 3: Donor funded politician and deforestation during term in office

\begin{tabular}{lcccc}
\hline & $(1)$ & $(2)$ & $(3)$ & $(4)$ \\
\hline Donor Funded & & & & \\
$\quad$ Robust p-value & $1.099^{* * *}$ & $0.627^{* *}$ & $1.290^{* *}$ & $0.972^{* *}$ \\
\multicolumn{1}{c}{ CI 95\% } & 0.008 & 0.019 & 0.026 & 0.021 \\
& {$[0.339,2.220]$} & {$[0.127,1.442]$} & {$[0.158,2.471]$} & {$[0.158,1.940]$} \\
Previous deforestation & & & & \\
Observations & 408 & $\checkmark$ & 408 & $\checkmark$ \\
Bandwidth obs. & 132 & 174 & 191 & 198 \\
Mean & 1.183 & 1.183 & 1.183 & 1.183 \\
Effect size (\%) & 92.90 & 53.00 & 109.05 & 82.16 \\
Bandwidth & 0.041 & 0.053 & 0.060 & 0.064 \\
(Local) polynomial order & 1 & 1 & 2 & 2 \\
\hline
\end{tabular}

Note: Columns 1 and 2 present the local linear estimates of average treatment effects at cut-off estimated with triangular kernel weights and optimal MSE bandwidth. Columns 3 and 4 presents the quadratic estimates of average treatment effects at cut-off estimated with triangular kernel weights and optimal MSE bandwidth. 95\% robust confidence intervals and robust p-values are computed following Calonico, Cattaneo and Titiunik (2014). Bandwidth obs. denotes number of observations in the optimal MSE bandwidth. The Effect Size (\%) is computed as the point estimate over the mean $\mathrm{x} 100$. Columns (2) and (4) include as covariate the measure of deforestation in the previous term (2008-2011). *** $\mathrm{p}<0.01,{ }^{* *} \mathrm{p}<0.05,{ }^{*} \mathrm{p}<0.1$.

\section{Figure 4: Different bandwidth sizes: Effect of electing a donor-funded politician on deforestation}

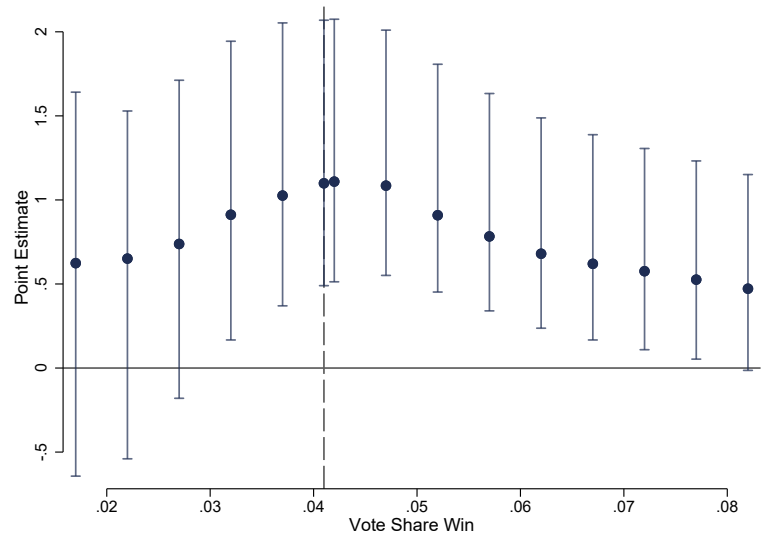

Panel A: Linear

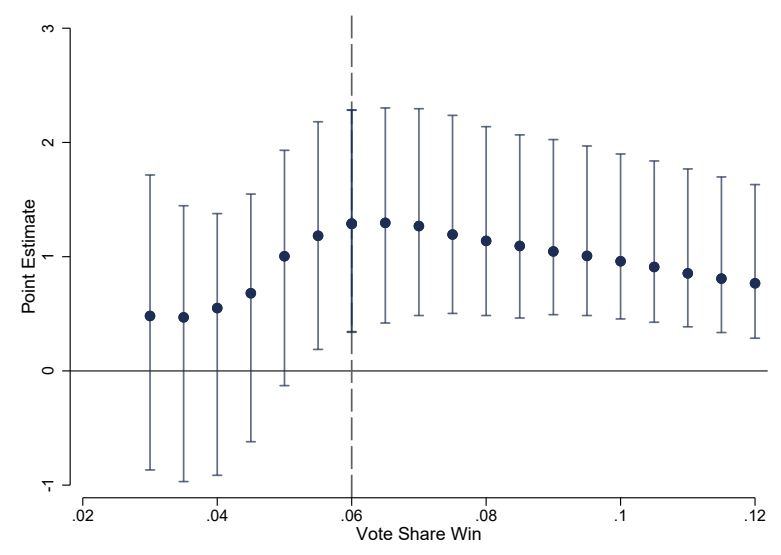

Panel B: Quadratic

Note: Estimates of average treatment effects at the cut-off, using triangular kernel weights. Optimal MSE bandwidths displayed in the dotted line. Following Cattaneo, Idrobo and Titiunik (2020), we display estimates between half and double the optimal bandwidth. Robust $90 \%$ confidence intervals estimated following Calonico, Cattaneo and Titiunik (2014).

Overall, these main effects provide compelling evidence that deforestation in Colombia increases in municipalities that elect donor-funded mayors. ${ }^{22}$ This in itself is an important finding. Defor-

\footnotetext{
${ }^{22}$ Results hold with OLS regressions using all 996 municipalities that elected mayors in 2011 (Appendix Table A4).
} 
estation is a key driver of climate change, and efforts to limit it are key to long-term environmental sustainability. Consequently, evidence highlighting political determinants of deforestation are crucial to the formulation of effective environmental protection policies.

\subsection{Mechanisms}

We argue that there are two primary channels through which the election of a donor-funded mayor could result in greater deforestation: contracting and regulatory non-enforcement. These channels are not mutually exclusive. Indeed, as highlighted by the example of the Calamar-Miraflores road discussed in the introduction, they may operate hand-in-hand, with contracts for infrastructure projects being accompanied by the selective non-enforcement of environmental regulations pertaining to the ensuing construction work. Nevertheless, we explore the extent to which each is driving the estimated effects.

\subsubsection{Contracting}

To examine the contracting channel we explore its implied temporal sequence, whereby any impact of electing a donor-funded mayor on contracting precedes the subsequent deforestation. First, in Table 4 we break down the main result by each year of the mayoral term. The positive effect is significant in all but the third year, and intensifies during the final year of the term. ${ }^{23}$ Although the estimated coefficient is substantially larger for the final year, in comparison to the average for self-funded mayors the difference is less stark. For year one, deforestation in municipalities with a donor-funded mayor is about $92.4 \%$ higher vis-a-vis municipalities that elected self-funded mayors, while for the last year it is $107.7 \%$ higher. ${ }^{24}$ It seems implausible that deforestation in year one, at least, derives from the contracting channel, since insufficient time would have passed for contacts to have been awarded and environmentally harmful work to have commenced. We explore this further by estimating the effect of electing donor-funded mayors on contracting outcomes.

Since infrastructure construction is a major state-related source of deforestation, we test whether

\footnotetext{
${ }^{23}$ Estimating a non-parametric differences-in-differences model we also see a large and significant increase in deforestation for the last year of the term (Appendix Figure A1).

${ }^{24}$ Similar results hold with a quadratic polynomial, although the relative effect size is more consistent across years one to three and then greater in year four (Appendix Table A5).
} 


\section{Table 4: Donor funded politician and deforestation by year of government}

\begin{tabular}{|c|c|c|c|c|}
\hline \multirow[t]{3}{*}{ 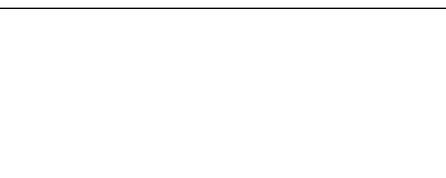 } & \multirow[t]{2}{*}{ (1) } & \multicolumn{2}{|c|}{$(2) \quad(3)$} & \multirow[t]{2}{*}{$(4)$} \\
\hline & & \multicolumn{2}{|c|}{ Year of government } & \\
\hline & 1 & 2 & 3 & 4 \\
\hline Donor Funded & $0.195^{* * *}$ & $0.220^{* *}$ & 0.117 & $0.490^{* * *}$ \\
\hline Robust p-value & 0.003 & 0.029 & 0.224 & 0.006 \\
\hline CI $95 \%$ & {$[0.077,0.376]$} & {$[0.027,0.504]$} & {$[-0.095,0.404]$} & {$[0.164,0.959]$} \\
\hline Observations & 408 & 408 & 408 & 408 \\
\hline Bandwidth obs. & 132 & 139 & 187 & 130 \\
\hline Mean & 0.211 & 0.306 & 0.211 & 0.455 \\
\hline Effect size $(\%)$ & 92.42 & 71.90 & 55.45 & 107.69 \\
\hline Bandwidth & 0.041 & 0.043 & 0.059 & 0.040 \\
\hline (Local) polynomial order & 1 & 1 & 1 & 1 \\
\hline
\end{tabular}

Note: Local linear estimates of average treatment effects at cut-off estimated with triangular kernel weights and optimal MSE bandwidth. 95\% robust confidence intervals and robust p-values are computed following Calonico, Cattaneo and Titiunik (2014). Bandwidth obs. denotes number of observations in the optimal MSE bandwidth.

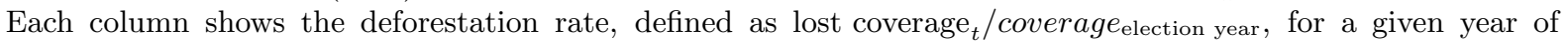
government. The Effect size $(\%)$ is computed as the point estimate over the mean $\mathrm{x} 100 . * * * \mathrm{p}<0.01, * * \mathrm{p}<0.05$, $* \mathrm{p}<0.1$.

there is a differential increase in the number and average value of infrastructure contracts. As Table 5 shows, we find no evidence that donor-funded mayors commission more infrastructure projects, but their election is related to an increase in the average value of infrastructure contracts, with the estimated effect corresponding to an increase of $109 \%$ over municipalities electing selffunded mayors. ${ }^{25}$ It is worth noting that contracts awarded to campaign donors have been found to involve significant over-costs (Ruiz, 2017), which suggests that the estimated increased average value of infrastructure contracts may not actually result in larger projects that could induce greater deforestation, but instead may simply increase the cost of similar projects to those undertaken in municipalities run by self-funded mayors. This possibility is reinforced by the fact that we see no significant increase in road density following election of donor-funded mayors, despite roads being a major component of infrastructure contracts, and the type of infrastructure project most likely to result in deforestation. We also look at contracts for mining and environmental work, both of which may be related to deforestation, but find no significant differences in their number or average value between municipalities electing self-funded and donor-funded mayors.

\footnotetext{
${ }^{25}$ Results are equivalent with a quadratic polynomial (Appendix Table A6).
} 
Table 5: Donor funded politician and contracts

\begin{tabular}{|c|c|c|c|c|c|c|c|}
\hline & (1) & $(2)$ & (3) & (4) & (5) & $(6)$ & (7) \\
\hline & \multicolumn{3}{|c|}{ Infrastructure } & \multicolumn{2}{|c|}{ Environmental } & \multicolumn{2}{|c|}{ Mining } \\
\hline & Number & Log Avg. value & $\begin{array}{c}\text { Road } \\
\text { construction }\end{array}$ & Number & Log Avg. value & Number & Log Avg. value \\
\hline Donor Funded & -30.151 & $1.091^{* *}$ & -0.015 & -4.904 & 0.486 & 0.209 & -0.307 \\
\hline Robust p-value & 0.357 & 0.017 & 0.346 & 0.742 & 0.150 & 0.637 & 0.672 \\
\hline CI $95 \%$ & {$[-127.980,46.163]$} & {$[0.219,2.258]$} & {$[-0.060,0.021]$} & {$[-55.157,39.293]$} & {$[-0.197,1.294]$} & {$[-0.774,1.265]$} & {$[-1.785,1.150]$} \\
\hline Observations & 401 & 400 & 401 & 401 & 366 & 401 & 145 \\
\hline Bandwidth obs. & 226 & 165 & 211 & 211 & 174 & 216 & 96 \\
\hline Mean & 140.896 & 4.818 & 0.015 & 18.197 & 3.795 & 0.976 & 3.618 \\
\hline Effect Mean $(\%)$ & -21.40 & 109 & -100 & -26.95 & 48.6 & 21.41 & -30.7 \\
\hline Bandwidth & 0.077 & 0.049 & 0.071 & 0.073 & 0.062 & 0.074 & 0.112 \\
\hline (Local) polynomial order & 1 & 1 & 1 & 1 & 1 & 1 & 1 \\
\hline
\end{tabular}

Note: Local linear estimates of average treatment effects at cut-off estimated with triangular kernel weights and optimal MSE bandwidth. 95\% robust confidence intervals and robust p-values are computed following Calonico, Cattaneo and Titiunik (2014). Bandwidth obs. denotes number of observations in the optimal MSE bandwidth. The average value of contracts was transformed using inverse hyperbolic sine. The contracts are catalogued in each category by analysing their reported object. For columns 1,3 , 4, and 6 , the effect size (\%) is computed as the point estimate over the mean $\mathrm{x} 100$, while for the rest of the columns is the point estimate $\mathrm{x} 100$. $^{* * *} \mathrm{p}<0.01$, ** $\mathrm{p}<0.05,{ }^{*} \mathrm{p}<0.1$.

Given the implied temporal sequence, we analyse the impact of electing a donor-funded politician on the value of infrastructure contracts by year of the mayoral term. Results in Appendix Table A7 show that the estimated coefficient is only significant in year three. Given the larger magnitude of the estimated effect on deforestation in year four, this finding is consistent with the claim that donor-funded mayors contribute to deforestation in part by awarding larger contracts for infrastructure projects. Therefore the contracting channel may explain part of the estimated effect of donor-funded mayors on deforestation that occurs in the final year of the mayoral term. ${ }^{26}$

In a final test of the contracting mechanism, we explore the extent to which infrastructure contracts relate to activities that can plausibly influence deforestation. Coding all infrastructure contracts, we find that only $27 \%$ were for activities that might affect deforestation, of which the vast majority were for road construction. ${ }^{27}$ These findings therefore suggest that the contracting channel alone cannot account for the overall effect of electing a donor-funded mayor on deforestation.

\footnotetext{
${ }^{26}$ Mediation analysis using sequential g-estimation (Acharya, Blackwell and Sen, 2016) finds almost no impact of infrastructure contracting as a potential mediator, suggesting that preferential contracting alone cannot explain the effect of electing a donor-funded mayor on deforestation (Appendix Figures A2 and A3).

${ }^{27}$ Many contracts were related to projects such as the construction of schools, hospitals, and sports centres, all in the pre-existing urban areas of municipalities. Table A8 presents estimates of the effect of electing a donor-funded mayor on infrastructure contracts separately for contacts that were and were not related to deforestation. Effects are slightly larger for contracts related to deforestation.
} 


\subsubsection{Regulatory non-enforcement}

We argue that these effects also result from donor-funded mayors rewarding donors with selective non-enforcement of environmental regulations. It is difficult to directly observe selective regulatory non-enforcement. One benefit of the RDD we employ is that, given the balance on pre-term municipal characteristics, we can be confident the observed differences in deforestation do not result from variation in previous enforcement capacity. However, the problem remaining is that we observe the outcome, deforestation, rather than directly observing compliance with or enforcement of environmental regulations. Our approach is therefore to explore a series of further implications of this mechanism. First, that selective non-enforcement of environmental regulations by mayors should be offset by alternative formal enforcement institutions. Second, that selective non-enforcement should be offset by informal enforcement actors. And third, that illegal deforestation is more likely to be accompanied by fires.

Alternative formal enforcement institutions. If donor-funded mayors turn a blind eye to their donors' illegal deforestation activities, the effect of electing donor-funded mayors on deforestation should be mitigated by the presence of alternative sources of environmental law enforcement. Where other enforcement institutions are present, selective non-enforcement by mayors should determine deforestation levels to a lesser extent. We investigate whether the effect of electing a donor-funded mayor is conditional on either of two alternative enforcement institutions: the CARs and the National Parks administration. We also test whether the main effect is attenuated by the number of offices of the Procurator General (Procuraduría) and of the Attorney General (Fiscalía), which we take as additional proxies for the extent of state presence within the municipality. Importantly, all measures capturing the presence of these alternative formal enforcement institutions vary smoothly at the cutoff (see Table 2).

As detailed in Section 3, part of Colombia's natural forest is designated protected area under the care of the National Parks administration, and is subject to more stringent regulation and monitoring overseen directly by the national government. ${ }^{28}$ This means that in areas designated as National Parks, responsibility for enforcement of environmental regulations falls less heavily on local municipal officials. Table 6 column 1 presents results from an analysis interacting donorfunded politician victory with a measure of area in square kilometres designated as National Parks

\footnotetext{
${ }^{28}$ Bonilla-Mejía and Higuera-Mendieta (2019) show that protected area designation reduces deforestation.
} 
in the municipality. Consistent with our interpretation, the estimated coefficient on the interaction term is negative and significant, indicating that an increase in National Parks area reduces the additional deforestation linked to electing a donor-funded mayor.

Table 6: Heterogeneous Effects: State Presence

\begin{tabular}{|c|c|c|c|c|c|c|}
\hline & & \multicolumn{5}{|c|}{ Measure $Z$} \\
\hline & & $\begin{array}{c}\text { National } \\
\text { Parks Area }\end{array}$ & $\begin{array}{l}\text { CAR } \\
\text { office }\end{array}$ & $\begin{array}{c}\text { Distance to } \\
\text { CAR }\end{array}$ & $\begin{array}{c}\text { Procurator } \\
\text { offices }\end{array}$ & $\begin{array}{c}\text { Attorney } \\
\text { offices }\end{array}$ \\
\hline \multirow[t]{2}{*}{ A } & Donor funded & $\begin{array}{l}1.117^{* *} \\
(0.439)\end{array}$ & $\begin{array}{l}1.195^{* *} \\
(0.466)\end{array}$ & $\begin{array}{l}-0.149 \\
(0.518)\end{array}$ & $\begin{array}{c}1.024^{* *} \\
(0.427)\end{array}$ & $\begin{array}{c}1.325^{* * *} \\
(0.496)\end{array}$ \\
\hline & $\mathrm{Z}$ & $\begin{array}{c}0.210^{* *} \\
(0.105)\end{array}$ & $\begin{array}{c}0.487 \\
(0.592)\end{array}$ & $\begin{array}{c}0.0003 \\
(0.0079)\end{array}$ & $\begin{array}{c}1.195^{* * *} \\
(0.175)\end{array}$ & $\begin{array}{l}0.215^{* *} \\
(0.0992)\end{array}$ \\
\hline B & $\mathrm{Z} \times$ Donor funded & $\begin{array}{c}-0.279^{*} \\
(0.144)\end{array}$ & $\begin{array}{c}-1.610^{*} \\
(0.966)\end{array}$ & $\begin{array}{c}0.0371^{* *} \\
(0.0153)\end{array}$ & $\begin{array}{c}-2.434^{* * *} \\
(0.245)\end{array}$ & $\begin{array}{c}-0.450^{* *} \\
(0.162)\end{array}$ \\
\hline \multicolumn{2}{|c|}{ Observations } & 408 & 408 & 408 & 408 & 408 \\
\hline \multicolumn{2}{|c|}{ Bandwidth obs. } & 132 & 132 & 132 & 132 & 132 \\
\hline \multicolumn{2}{|c|}{ R-squared } & 0.051 & 0.062 & 0.209 & 0.053 & 0.067 \\
\hline \multicolumn{2}{|c|}{ Bandwidth } & 0.041 & 0.041 & 0.041 & 0.041 & 0.041 \\
\hline \multicolumn{2}{|c|}{ (Local) polynomial order } & 1 & 1 & 1 & 1 & 1 \\
\hline \multicolumn{2}{|c|}{$\mathrm{A}+\mathrm{B}$} & 0.838 & -0.416 & -0.111 & -1.410 & 0.875 \\
\hline \multicolumn{2}{|c|}{ Effect size (\%) } & 93.09 & -35.04 & -15.12 & -72.136 & 102.267 \\
\hline \multicolumn{7}{|c|}{ Ho: $A+B=0$} \\
\hline \multicolumn{2}{|c|}{ F-statistic } & 4.39 & 0.24 & 0.05 & 34.5 & 4.7 \\
\hline \multicolumn{2}{|c|}{ P-value } & 0.04 & 0.62 & 0.83 & 0.05 & 0.30 \\
\hline
\end{tabular}

Note: OLS regression weighted by a triangular kernel within the MSE optimal bandwidth sample and controlling for a linear polynomial. Bandwidth obs. denotes number of observations in the optimal MSE bandwidth. The dependent variable is deforestation during the full term. National Parks area is defined as the total area with national parks in the municipality, CAR office is a dummy that takes the value one if there was at least on CAR office in the municipality, Distance to CAR is the distance to the closest CAR, Procurator offices is the number of offices of the Procurator General (Procuraduría), and Attorney offices is the number of offices of the Attorney General (Fiscalía). The Effect size (\%) is computed as $100 x(A+B) /\left(\right.$ constant $\left.+\beta_{Z}\right) .{ }^{* * *} \mathrm{p}<0.01,{ }^{* *} \mathrm{p}<0.05,{ }^{*}$ $\mathrm{p}<0.1$.

Section 3 also detailed the CARs significant role in monitoring and enforcing environmental regulations across Colombia. While CARs delegate much of this responsibility to territorial governments, their own offices still play an important role in enforcement. Therefore, we study how the presence of and distance to CAR offices mediate the effects of victory by donor-funded mayors on deforestation. Columns 2 and 3 in Table 6 show estimates where the indicator of donor-funded politician victory is interacted with a dummy for the presence of a CAR office in the municipality, and with the distance to the closest CAR office from the centroid of the municipality, respectively. Once again, the results support the regulatory non-enforcement channel. The presence of CAR offices significantly diminishes the effect of a donor-funded victory on deforestation. Meanwhile, 
the greater the distance to the CAR offices, the greater the increase in deforestation when a donorfunded politician is elected.

We also explore whether there is heterogeneity in the main effects according to the number of offices of the Procurator General (Procuraduría) and of the Attorney General (Fiscalía). As shown in Table 6, the coefficients on the interaction terms between both these additional measures and victory by a donor-funded politician are negative and significant. These findings, therefore, add further weight to the idea that the presence of alternative formal enforcement institutions mitigates the impact of selective regulatory non-enforcement by donor-funded mayors.

Informal enforcement institutions. Landowners and cattle ranchers benefit from selective regulatory enforcement by exploiting land with greater intensity. The activities of these local elites have long been affected by the dynamics of internal conflict in Colombia. As such, we posit that an additional source of alternative regulatory enforcement comes from informal institutions, in particular illegal armed groups.

As discussed in Section 3, the lasting presence of illegal armed actors in Colombia is closely connected to conflict over land, with the actions of guerrilla groups such as the FARC often justified by a desire to push back against inequality exacerbated by land expropriation by local elites. Partly in response, far-right paramilitary groups have frequently acted to protect and promote the economic interests of these elites. Given this history, we consider these armed groups as representing informal institutions for the enforcement of environmental protection. Specifically, because guerrilla groups have often obstructed and attacked the business of elites, we expect their presence to limit illegal deforestation by local elites, thereby offsetting selective non-enforcement of environmental regulations by donor-funded mayors. The presence of paramilitary groups, on the other hand, should have no such effect.

Taking pre-term attacks by these two types of armed groups as proxies for their presence in a municipality, we study how this affects our main result. As with formal institutions, the measures capturing presence of these informal enforcement institutions also vary smoothly at the cutoff (see Table 2). Table 7 presents estimated effects of the impact of a donor-funded politician on deforestation, conditional on number of attacks by each type of group in the municipality. ${ }^{29}$ The results are consistent with the historical alignment of armed groups with local elites. While

\footnotetext{
${ }^{29}$ Results hold with a quadratic polynomial (Appendix Table A9).
} 
attacks by guerrilla groups mitigate the increase in deforestation linked to a donor-funded victory, paramilitary attacks have no such impact. Taking attacks by guerrilla groups as a proxy for the presence of informal institutions providing checks on illegal deforestation by local elites, therefore, these findings provide further evidence in support of the regulatory non-enforcement mechanism. ${ }^{30}$

\section{Table 7: Heterogeneous Effects: Armed Conflict}

\begin{tabular}{|c|c|c|c|}
\hline & \multirow{2}{*}{\multicolumn{2}{|c|}{$\begin{array}{c}(1) \\
\text { Attacks measure } Z\end{array}$}} \\
\hline & & & \\
\hline & & Paramilitary & Guerrilla \\
\hline \multirow[t]{4}{*}{ A } & Donor funded & $0.704^{*}$ & $1.133^{* * *}$ \\
\hline & & $(0.422)$ & $(0.427)$ \\
\hline & $\mathrm{Z}$ & 0.116 & $0.574^{* * *}$ \\
\hline & & $(0.139)$ & $(0.187)$ \\
\hline \multirow[t]{2}{*}{ B } & $\mathrm{Z} \times$ Donor funded & 0.123 & $-0.623^{* *}$ \\
\hline & & $(0.153)$ & $(0.241)$ \\
\hline \multicolumn{2}{|c|}{ Observations } & 408 & 408 \\
\hline \multicolumn{2}{|c|}{ Bandwidth obs. } & 132 & 132 \\
\hline \multicolumn{2}{|c|}{ R-squared } & 0.116 & 0.131 \\
\hline \multicolumn{2}{|c|}{ Bandwidth } & 0.041 & 0.041 \\
\hline \multicolumn{2}{|c|}{ (Local) polynomial order } & 1 & 1 \\
\hline \multicolumn{2}{|c|}{$\mathrm{A}+\mathrm{B}$} & 0.827 & 0.510 \\
\hline \multicolumn{2}{|c|}{ Effect size $(\%)$} & 90.17 & 42.86 \\
\hline \multicolumn{4}{|c|}{ Ho: $A+B=0$} \\
\hline \multicolumn{2}{|c|}{ F-statistic } & 4.60 & 1.37 \\
\hline \multicolumn{2}{|c|}{ P-value } & 0.03 & 0.24 \\
\hline
\end{tabular}

Note: OLS regression weighted by a triangular kernel within the MSE optimal bandwidth sample and controlling for a quadratic polynomial. Bandwidth obs. denotes number of observations in the optimal MSE bandwidth. The dependent variable is deforestation during the full term. Paramilitary (Guerrilla) attacks is the number of paramilitary (guerrilla) attacks during the previous term (2008-2011). The Effect size (\%) is computed as $100 x(A+B) /\left(\right.$ constant $\left.+\beta_{Z}\right)$. $* * * \mathrm{p}<0.01, * * \mathrm{p}<0.05, * \mathrm{p}<0.1$.

Fires. In Colombia and elsewhere, fire clearance of forest areas for cattle ranching and cultivation is widespread, and this environmentally harmful practice is regulated by the law. ${ }^{31}$ Moreover, intensive fire clearance practices are much more likely to be employed for illegal land grabbing linked to cattle ranching and cultivation than for government-contracted infrastructure projects.

\footnotetext{
${ }^{30}$ These results could also reflect underlying elite preferences for infrastructure projects across areas with paramilitaries/guerrillas, although evidence of a differential increase in deforestation in FARC-controlled areas following the ceasefire suggest otherwise (Prem, Saavedra and Vargas, 2020).

${ }^{31}$ See for example, https ://news . mongabay.com/2019/09/as-the-amazon-burns-colombias-forests-decimated -for-cattle-and-coca/ and https://theecologist.org/2020/aug/17/deforestation-colombia. Last accessed June 2021.
} 
Therefore, we check for an increase in the intensity of forest fires in municipalities governed by donor-funded mayors. A differential increase in fire intensity would strongly indicate unregulated land exploitation through fire clearance. Following the same RDD approach described above, we test for a discontinuous jump in fire intensity, measured as average fire brightness, when a donorfunded mayor is elected. Table 8 presents results consistent with our interpretation; we find an increase in average fire intensity of $32.9 \%$ when a donor-funded mayor is elected. Results are robust to selecting linear or quadratic polynomials (Table A10) and hold across a range of bandwidths (Figure A4). ${ }^{32}$

\section{Table 8: Donor funded politician and fire intensity}

\begin{tabular}{lcc}
\hline & $(1)$ & $(2)$ \\
\hline & & \\
Donor Funded & $80.976^{*}$ & $75.464^{* *}$ \\
$\quad$ Robust p-value & 0.059 & 0.041 \\
CI 95\% & {$[-3.381,181.446]$} & {$[3.189,156.092]$} \\
& & \\
Previous fire intensity & & $\checkmark$ \\
Observations & 408 & 408 \\
Bandwidth obs. & 195 & 198 \\
Mean & 246.141 & 30.141 \\
Effect size (\%) & 32.90 & 0.063 \\
Bandwidth & 0.061 & 1 \\
(Local) polynomial order & 1 & \\
\hline
\end{tabular}

Note: Local linear estimates of average treatment effects at cut-off estimated with triangular kernel weights and optimal MSE bandwidth. 95\% robust confidence intervals and robust p-values are computed following Calonico, Cattaneo and Titiunik (2014). Bandwidth obs. denotes number of observations in the optimal MSE bandwidth. Column (2) includes as covariate the measure of fire intensity from the previous term (2009-2011), being 2009 the first year with data availability. Fire intensity is measured as the average brightness of fires in a municipality. The Effect size $(\%)$ is computed as the point estimate over the mean $\mathrm{x} 100{ }^{* * *} \mathrm{p}<0.01,{ }^{* *} \mathrm{p}<0.05,{ }^{*} \mathrm{p}<0.1$.

Disaggregating the estimates of fire intensity shows this effect is concentrated in the final year (Appendix Table A11). This behaviour may be consistent with an increase in illegal deforestation towards the end of the term as perpetrators seek to maximise extraction before their preferred mayor leaves office, due to the potential increased risk of punishment under a future mayor. Indeed, this fits with additional evidence that municipalities electing donor-funded mayors see a significant increase in the chamber of commerce registration of agro-cattle firms, which are known for the use of fire clearance practices, and that this effect is concentrated in the final year of the mayoral term

\footnotetext{
${ }^{32}$ Mediation analysis suggests around $20 \%$ of the estimated effect of donor-funded mayors on deforestation operates through fire clearance (Appendix Figure A2).
} 
(Tables A12 and A13). ${ }^{33}$ Moreover, it suggests that the increase in deforestation in the final year of the mayoral term (shown in Table 4) is not solely due to an increase in the average value of infrastructure contracts. ${ }^{34}$

\subsection{Alternative explanations}

This section addresses two alternative mechanisms that could plausibly explain increased deforestation following the election of donor-funded mayors: variation in agricultural pressure, and candidate characteristics. ${ }^{35}$

\subsubsection{Agricultural pressure}

Deforestation could reflect the level of pressure from local agricultural interests to access potential agricultural land. By this mechanism, donations are used to buy access to land, rather than buy reductions in regulatory enforcement. This is unlikely because powers to grant land access via environmental concessions or licenses rests with CARs, not with mayors themselves. The environmental role of municipal governments lies primarily in the local enforcement of regulations through policing and sanctioning regulatory violations. Nevertheless, we explore the potential impact of agricultural pressure empirically, in several ways.

First, in Table 2, we show there is no discontinuity at the cutoff for a variety of measures capturing pre-term levels of agricultural pressure, including hectares of forest coverage and agricultural land, and levels of agricultural production. Second, our main results and the heterogeneous effects based on National Parks area and CAR presence are all robust to the inclusion of controls for the aforementioned agricultural pressure measures (Appendix Tables A14 and A15). Third, the results also hold when we weight observations using pre-term forest coverage or municipality area, thus giving the same weight to each square kilometer (Appendix Table A16). Finally, we find no evidence of differential effects of electing a donor-funded mayor on deforestation according to pre-term

\footnotetext{
${ }^{33}$ For reports on the use of fire clearance by agro-businesses, see: https://www.eltiempo.com/vida/medio -ambiente/opinion-480690, and https://es.mongabay.com/2019/07/incendios-norte-amazonia-deforestacion -colombia/. Last accessed June 2021.

${ }^{34}$ This temporal pattern is also consistent with fire clearance being used in the final year to make way for infrastructure projects contracted in year three.

${ }^{35}$ We are grateful to anonymous reviewers for suggesting these.
} 
measures of agricultural pressure (Appendix Table A17).

\subsubsection{Candidate characteristics}

While our research design identifies the effect of candidates being supported by donors, it is possible that donations are directed towards candidates with particular characteristics, as opposed to donations inducing particular behavior (i.e., regulatory non-enforcement) from candidates. This raises a second possible alternative mechanism: that donors support candidates who are more sceptical of environmental regulation and less willing to enforce regulations strictly. Several empirical results help rule this out.

First, Table 2 shows that covariates measuring candidate characteristics are all smooth at the cut-off, suggesting donations are not targeted to candidates based on these characteristics. This includes ideology, which likely captures much of the variation in candidates' attitudes towards environmental regulation. It also includes measures of candidates' prior political experience, and of whether they have previously registered to vote illegally. These are intended to capture prior history of, or greater proclivity for, malfeasance in office, respectively. Second, we show our main results are robust to controlling for these measures (Appendix Table A14).

Third, we find no evidence that deforestation is affected by the election of a right-wing politician (Appendix Table A18), which shows that electing more conservative candidates does not itself lead to greater deforestation, as this alternative mechanism would imply. ${ }^{36}$ Finally, we find no evidence of differential effects of electing a donor-funded mayor on deforestation according to candidates' ideology, prior experience, or history of illegally registering to vote (Appendix Table A19). This suggests that even among conservative candidates, or those with a proclivity for malfeasance, donor-supported candidates cause more deforestation.

\footnotetext{
${ }^{36}$ We also see no evidence that deforestation is affected by the election of a candidate with prior political experience (Appendix Table A20). The number having registered to vote illegally is too small to estimate the effect of electing a candidate who has done this.
} 


\section{Conclusions}

We provide evidence that in Colombia, the election of mayors who rely on campaign donations significantly increases deforestation. In line with existing literature, we show that this may be due in part to differential contracting practices, because the average value of infrastructure contracts increases with the election of a donor-funded mayor. But temporal dynamics demonstrate that the more standard contracting story only partially explains the estimated effects. Instead, we provide evidence consistent with the argument that campaign donations also influence deforestation through another unexplored channel: by purchasing regulatory non-enforcement. Donor-funded mayors turn a blind eye to activities resulting in illegal deforestation in return for campaign contributions.

The RDD alleviates endogeneity concerns and gives us confidence that the estimated effect of electing a donor-funded politician on deforestation is identified. This finding is important in itself, because it provides clear evidence of the political dynamics affecting deforestation, a central driver of environmental degradation and climate change. One key benefit of the RDD is to rule out the possibility that this variation is due to differences in pre-existing institutional enforcement capacity across municipalities. Disaggregating by year shows this effect is present across the mayoral term, and that differential contracting practices can only explain the effect observed in the final year, and even then only partially so. We argue that the remainder of the overall effect results from the selective non-enforcement of environmental regulations by mayors rewarding their donors.

Although we cannot observe enforcement by mayors directly, we present a range of additional evidence consistent with this interpretation. First, we demonstrate that the effect of victory by a donor-funded politician on deforestation is attenuated by the presence of alternative formal enforcement institutions (which are beyond the mayor's control). Second, we show that the effect is also mitigated by the presence of illegal armed groups that serve as informal enforcement actors. Finally, because illegal deforestation frequently makes use of aggressive fire-clearance practices, we show that fire intensity is significantly higher in municipalities that elect donor-funded mayors. Taken together, this range of evidence supports our interpretation that campaign donors in Colombia purchase regulatory non-enforcement by mayors, allowing them to exploit land in a way that increases deforestation. Although the available evidence is compelling, future work could bolster these findings with qualitative evidence garnered through enforcement process tracing (Bozçağa and Holland, 2018). 
The findings make a number of important contributions. First, they advance the literature on the influence of money in politics, moving beyond a focus on favorable legislation and preferential contracting to acknowledge that campaign donations may also influence regulatory enforcement. In doing so, they contribute to the work on state capture by highlighting campaign finance as another means by which economic elites may exert disproportionate influence over the local state. And finally, the findings increase our understanding of the political dynamics of deforestation, and of environmental degradation more broadly. This matters, because learning how political competition and incentives influence the implementation of environmental regulations is vital if we are to effectively counter the challenge of climate change. 


\section{References}

Acemoglu, Daron, Davide Ticchi and Andrea Vindigni. 2011. "Emergence and persistence of inefficient states." Journal of the European Economic Association 9(2):177-208.

Acharya, Avidit, Matthew Blackwell and Maya Sen. 2016. "Explaining causal findings without bias: Detecting and assessing direct effects." American Political Science Review 110(3):512-529.

Aklin, Michaël, Patrick Bayer, SP Harish and Johannes Urpelainen. 2014. "Who blames corruption for the poor enforcement of environmental laws? Survey evidence from Brazil." Environmental Economics and Policy Studies 16(3):241-262.

Austen-Smith, David and John R. Wright. 1994. "Counteractive Lobbying." American Journal of Political Science 38(1):25-44.

Balboni, Clare, Robin Burgess, Anton Heil, Jonathan Old and Benjamin A. Olken. 2021. "Cycles of Fire? Politics and Forest Burning in Indonesia." AEA Papers and Proceedings 111:415-19.

Blackman, Allen, Richard Morgenstern and Elizabeth Topping. 2006. "Institutional Analysis of Colombia's Autonomous Regional Corporations (CARs)." Resources for the Future, Tech. rep.

Boas, Taylor C, F Daniel Hidalgo and Neal P Richardson. 2014. "The spoils of victory: campaign donations and government contracts in Brazil." The Journal of Politics 76(2):415-429.

Bonan, Gordon B. 2008. "Forests and Climate Change: Forcings, Feedbacks, and the Climate Benefits of Forests." Science 320(5882):1444-1449.

Bonilla-Mejía, Leonardo and Iván Higuera-Mendieta. 2019. "Protected areas under weak institutions: Evidence from Colombia." World Development 122:585-596.

Bozçağa, Tuğba and Alisha C Holland. 2018. "Enforcement Process Tracing: Forbearance and Dilution in Urban Colombia and Turkey." Studies in Comparative International Development $53(3): 300-323$.

Bulte, Erwin H., Richard Damania and Ramon Lopez. 2007. "On the gains of committing to inefficiency: Corruption, deforestation and low land productivity in Latin America." Journal of Environmental Economics and Management 54(3):277 - 295. 
Burgess, Robin, Matthew Hansen, Benjamin A. Olken, Peter Potapov and Stefanie Sieber. 2012. "The Political Economy of Deforestation in the Tropics*." The Quarterly Journal of Economics 127(4):1707-1754.

Calonico, Sebastian, Matias D. Cattaneo and Rocio Titiunik. 2014. "Robust Nonparametric Confidence Intervals for Regression-Discontinuity Designs." Econometrica 82(6):2295-2326.

Canay, Ivan A and Vishal Kamat. 2018. "Approximate permutation tests and induced order statistics in the regression discontinuity design." The Review of Economic Studies 85(3):15771608.

Casas-Zamora, Kevin and Elin Falguera. 2016. "Political finance and the equal participation of women in Colombia: a situation analysis." International Institute for Democracy and Electoral Assistance.

Cattaneo, Matias D., Michael Jansson and Xinwei Ma. 2018. "Manipulation testing based on density discontinuity." Stata Journal 18(1):234-261.

Cattaneo, Matias D., Nicolás Idrobo and Rocío Titiunik. 2020. A Practical Introduction to Regression Discontinuity Designs: Foundations. Elements in Quantitative and Computational Methods for the Social Sciences Cambridge University Press.

Colonnelli, Emanuele, Mounu Prem and Edoardo Teso. 2020. "Patronage and selection in public sector organizations." American Economic Review 110(10):3071-99.

Curtis, Philip G., Christy M. Slay, Nancy L. Harris, Alexandra Tyukavina and Matthew C. Hansen. 2018. "Classifying drivers of global forest loss." Science 361(6407):1108-1111.

FAO. 2006. "Livestock Polici Brief 03: Cattle Ranching and Deforestation." Available at: http://www.fao.org/3/a-a0262e.pdf, accessed 17-Sep-2019.

Fernandez, Manuel. 2012. "Violencia y derechos de propiedad: El caso de la violencia en Colombia." Revista ESPE - Ensayos Sobre Politica Economica 30(69):112-147.

Global Forest Watch. 2019. "Natural forest in Colombia." www.globalforestwatch.org. [Online; accessed 17-Sep-2019].

Gulzar, Saad, Apoorva Lal and Benjamin Pasquale. 2021. "Representation and Forest Conservation: Evidence from India's Scheduled Areas.". 
Gulzar, Saad, Thomas S Robinson and Nelson A Ruiz. 2020. "How Campaigns Respond to Ballot Position: A New Mechanism for Order Effects." Journal of Politics .

Guzmán, G., O. Fals Borda and E Umaña. 2010. La violencia en Colombia. Vol. 1.

Hansen, M. C., P. V. Potapov, R. Moore, M. Hancher, S. A. Turubanova, A. Tyukavina, D. Thau, S. V. Stehman, S. J. Goetz, T. R. Loveland, A. Kommareddy, A. Egorov, L. Chini, C. O. Justice and J. R. G. Townshend. 2013. "High-Resolution Global Maps of 21st-Century Forest Cover Change." 342(6160):850-853.

Holland, Alisha C. 2016. "Forbearance." American Political Science Review 110(2):232-246.

Holland, Alisha C. 2017. Forbearance as redistribution: The politics of informal welfare in Latin America. Cambridge: Cambridge University Press.

Hollenbach, Florian M and Thiago N Silva. 2019. "Fiscal capacity and inequality: Evidence from Brazilian municipalities." The Journal of Politics 81(4):1434-1445.

Hurwicz, Leonid. 2008. "But who will guard the guardians?" American Economic Review 98(3):577-85.

Ibañez, Ana and Juan Muñoz-Mora. 2010. The Persistence of Land Concentration in Colombia: What Happened Between 2000 and 2009?

Lee, David S. and Thomas Lemieux. 2010. "Regression Discontinuity Designs in Economics." Journal of Economic Literature 48(2):281-355.

LeGrand, C. 1988. Colonización y protesta campesina en Colombia (1850-1950). Vol. 1 Centro editorial Universidad Nacional de Colombia.

Li, Quan and Rafael Reuveny. 2006. "Democracy and Environmental Degradation." International Studies Quarterly 50(4):935-956.

McCrary, Justin. 2008. "Manipulation of the running variable in the regression discontinuity design: A density test." Journal of Econometrics 142(2):698-714.

MOE. 2018. Democracias Empeñadas. Bogotá D. C. Colombia :: MOE.

Montes Cortés, Carolina. 2018. La corrupción en el sector ambiental: un detrimento contra el patrimonio natural. Bogotá: Universidad Externado de Colombia, 2018. 
Morjaria, Ameet. 2012. "Electoral Competition and Deforestation: Evidence From Kenya.".

Olken, Benjamin A and Rohini Pande. 2012. "Corruption in developing countries." Annu. Rev. Econ. 4(1):479-509.

Pachón, Mónica and Fabio Sánchez. 2014. Base de datos sobre resultados electorales CEDE, 1958 - 2011. Documentos CEDE 012058 Universidad de los Andes - CEDE.

Pailler, Sharon. 2018. "Re-election incentives and deforestation cycles in the Brazilian Amazon." Journal of Environmental Economics and Management 88:345 - 365.

Prem, Mounu, Andrés Rivera, Dario Romero and Juan F Vargas. 2022. "Selective civilian targeting: The unintended consequences of partial peace." Quarterly Journal of Political Science 17(3).

Prem, Mounu, Santiago Saavedra and Juan F Vargas. 2020. "End-of-conflict deforestation: Evidence from Colombia's peace agreement." World Development 129:104852.

Restrepo, Jorge, Michael Spagat and Juan Vargas. 2004. "The Dynamics of the Columbian Civil Conflict: A New Dataset." Homo Oeconomicus 21:396-429.

Ruiz, Nelson. 2017. "The Power of Money. The Consequences of Electing a Donor Funded Politician.".

Sánchez-Talanquer, Mariano. 2020. "One-Eyed State: The Politics of Legibility and Property Taxation." Latin American Politics and Society 62(3):65-93.

Sanford, Luke. 2021. "Democratization, Elections, and Public Goods: The Evidence from Deforestation." American Journal of Political Science .

Snyder, Jr., James M. 1990. "Campaign contributions as investments: The US House of Representatives, 1980-1986." Journal of Political Economy 98(6):1195.

Stratmann, Thomas. 2005. "Some talk: Money in politics. A (partial) review of the literature." Policy challenges and political responses pp. 135-156.

UNODC. 2016. "Monitoreo de territorios afectados por cultivos ilıcitos 2015." Tech. rep.

Zhu, Zaichun, Shilong Piao, Ranga B Myneni, Mengtian Huang, Zhenzhong Zeng, Josep G Canadell, Philippe Ciais, Stephen Sitch, Pierre Friedlingstein, Almut Arneth et al. 2016. "Greening of the Earth and its drivers." Nature Climate Change 6(8):791-795. 


\section{APPENDIX (For Online Publication)}

\section{List of Figures}

A1 Donor-funded politician on deforestation: Non-parametric DiD . . . . . . . . i i

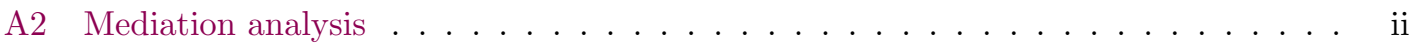

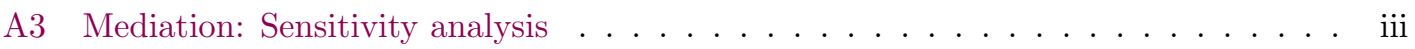

A4 Different bandwidth sizes. Donor funded politician and fire intensity . . . . . . . . iv

\section{List of Tables}

A1 More stringent donor-funded politician definition $\ldots \ldots \ldots \ldots \ldots$

A2 Difference between RD sample and rest of the country . . . . . . . . . v vi

A3 Donor funded politician and deforestation during term in office: Cubic polynomial vii

A4 Donor funded politician and deforestation: OLS . . . . . . . . . . viii

A5 Donor funded politician and deforestation ratio-Quadratic Polynomial ...... ix

A6 Donor funded politician and contracts: Quadratic polynomial . . . . . . . . . . x

A7 Donor funded politician and avg. value of infrastructure contracts per year . . . xi

A8 Donor funded politician and infrastructure contracts by relation to deforestation . xii

A9 Heterogeneous Effects: Armed Conflict - Quadratic Polynomial . . . . . . . . . . xiii

A10 Donor funded politician and fire intensity - Quadratic polynomial . . . . . . . . xiv

A11 Donor funded politician and fire intensity by year of government $\ldots \ldots \ldots$ xv

A12 Donor funded politician and agro-cattle firms entry by year $\ldots \ldots \ldots \ldots$. . . xvi

A13 Donor funded politician and agro-cattle firms entry by year - Quadratic . . . . . xvii

A14 Donor funded politician and deforestation during term in office: Adding covariates xviii

A15 Heterogeneous effects by state presence controlling for agricultural pressure . . . . xix

A16 Donor funded politician and deforestation during term in office: Using different

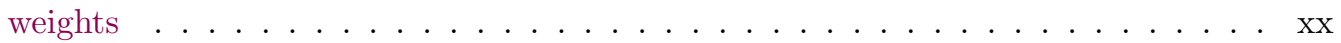

A17 Heterogeneous effects by agricultural presence . . . . . . . . . . . . . xxi

A18 Right-wing politician and deforestation during term in office . . . . . . . . xxii

A19 Heterogeneous effects by candidate characteristics . . . . . . . . . . . . xxiii 
A20 Politically experienced politician and deforestation during term in office . . . . . xxiv

A21 Heterogeneous Effects: State Presence - Quadratic Polynomial . . . . . . . . . . xxv

A22 Donor funded politician and infrastructure contracts by year of government -

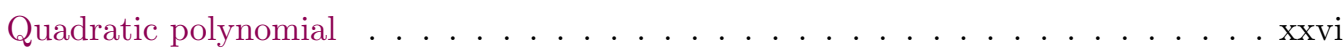

A23 Donor funded politician and fire intensity by year of government - Quadratic poly-

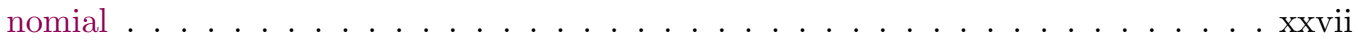

A24 Heterogeneous effects: Guerrilla presence and ceasefire . . . . . . . . . . . . . . xxviii

A25 Descriptive statistics for donor-funded politicians . . . . . . . . . . . . . . xxix

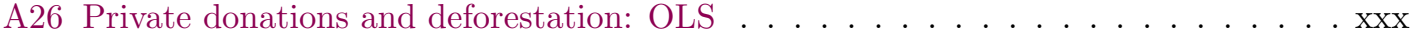




\section{Figure A1: Donor-funded politician on deforestation: Non-parametric DiD}

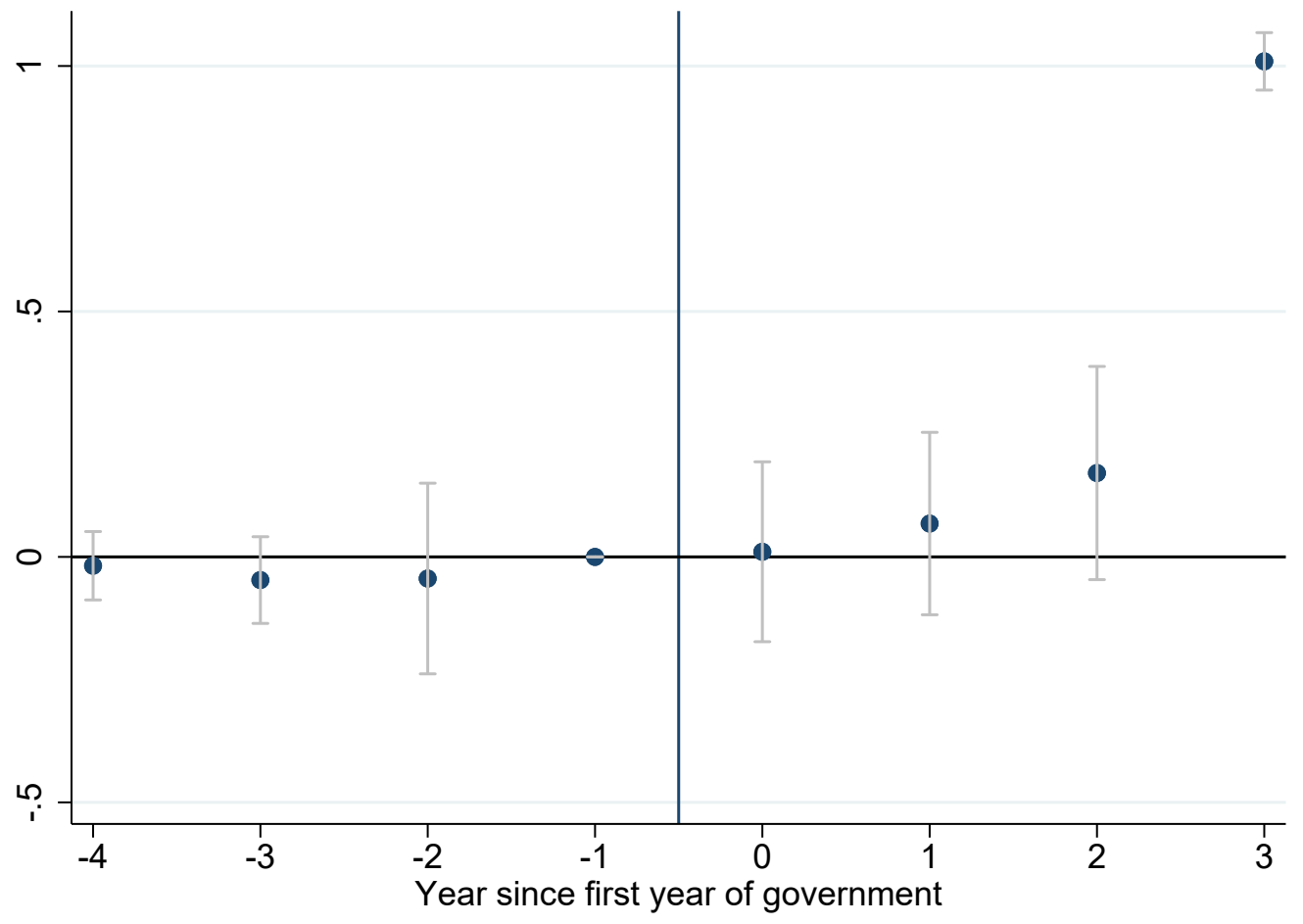

Note: We perform a non-parametric difference-in-differences interacting the treatment by the year dummy. $90 \%$ confidence intervals. The year zero represents the first year of government and the year -1 , is the election year. We use the full sample 408 of races between donor-funded and non-donor-funded top candidate. 
Figure A2: Mediation analysis

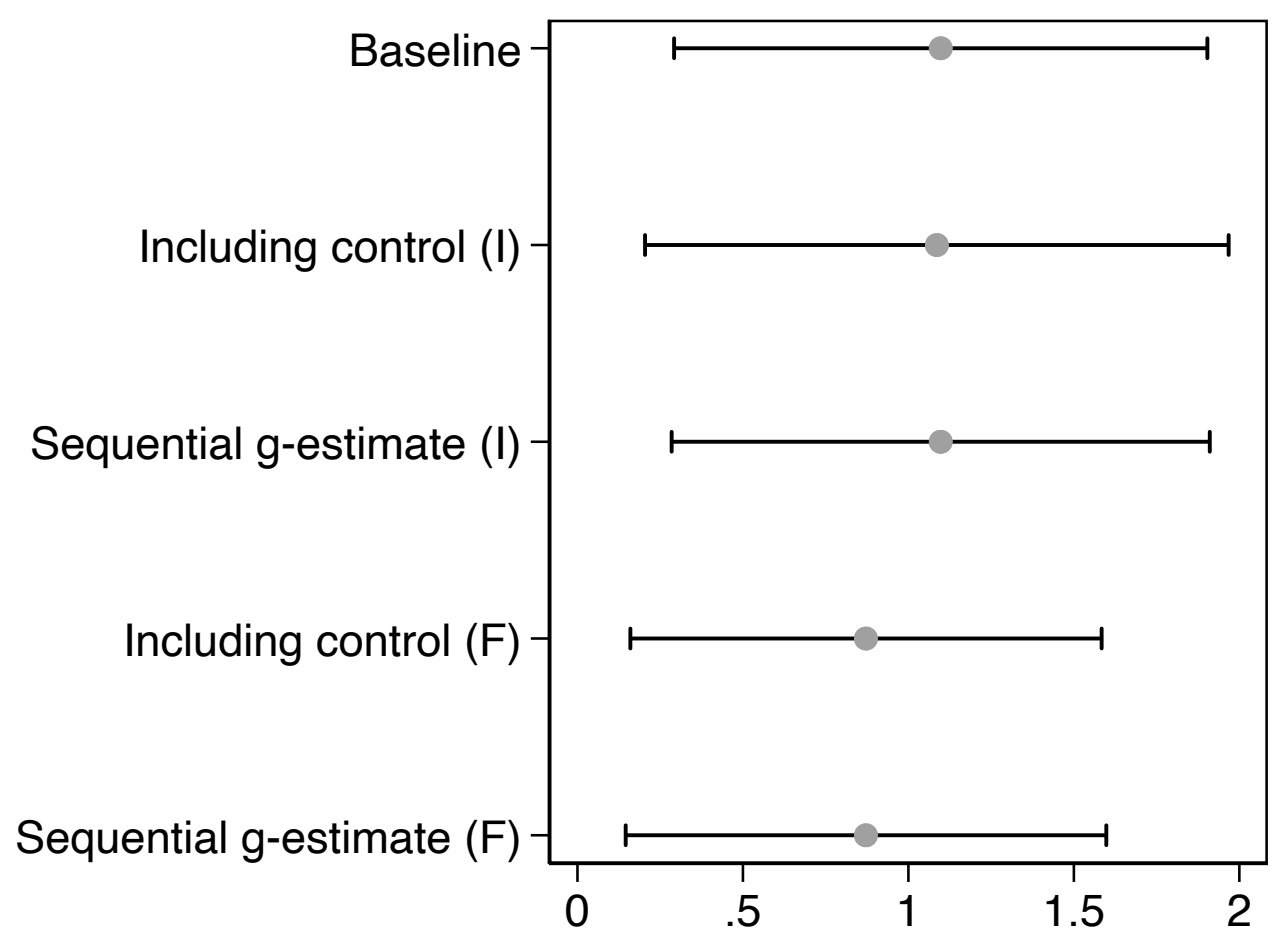

Note: This figure presents the mediation analysis for expenditures in infrastructure and fires. Baseline presents the point estimate and the $95 \%$ confidence interval for our baseline specification from column 1 Table 3 . Including control (I) presents the point estimate and the $95 \%$ confidence interval for the main specification but adding the hyperbolic sine transformation of the average value of expenditures on infrastructure after the election as a control. Sequential g-estimate (I) presents the point estimate and the $95 \%$ confidence interval for the sequential g-estimate suggested by Acharya, Blackwell and Sen (2016) using as a mediator the hyperbolic sine transformation of the average value of expenditures on infrastructure after the election. Including control $(F)$ presents the point estimate and the $95 \%$ confidence interval for the main specification but adding the number of fires after the election as a control. Sequential g-estimate $(F)$ presents the point estimate and the $95 \%$ confidence interval for the sequential g-estimate suggested by Acharya, Blackwell and Sen (2016) using as a mediator the number of fires after the election. In the case of the Sequential g-estimate (I), we construct the confidence intervals using a non-parametric bootstrap procedure that includes the two estimation stages as suggested by the authors. 
Figure A3: Mediation: Sensitivity analysis
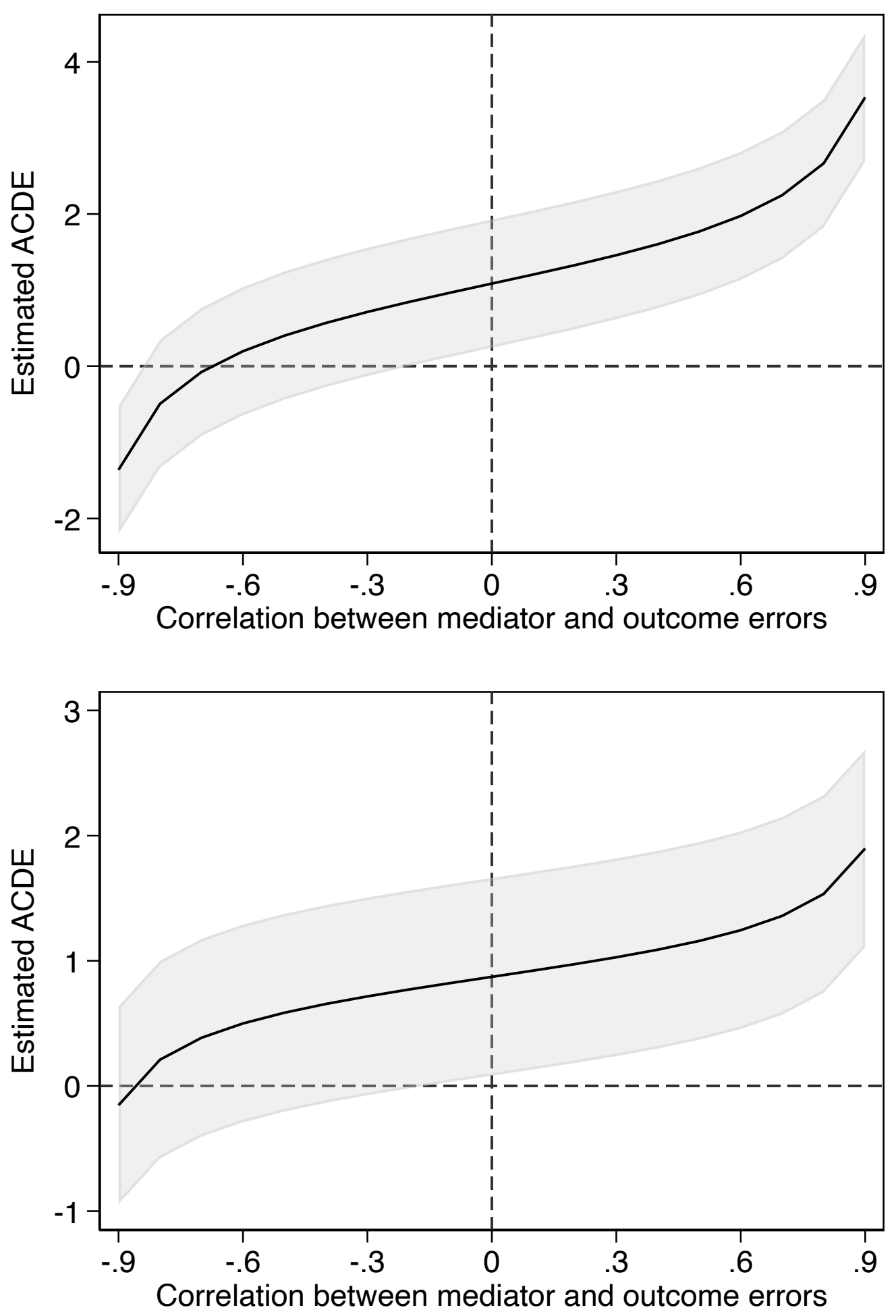

Note: This figure presents the sensitivity analysis for the mediation analysis for expenditures on infrastructure (Panel A) and fires (Panel B) as suggested by Acharya, Blackwell and Sen (2016). We construct the confidence intervals using a non-parametric bootstrap procedure that includes the two estimation stages as suggested by the authors. 
Figure A4: Different bandwidth sizes. Donor funded politician and fire intensity

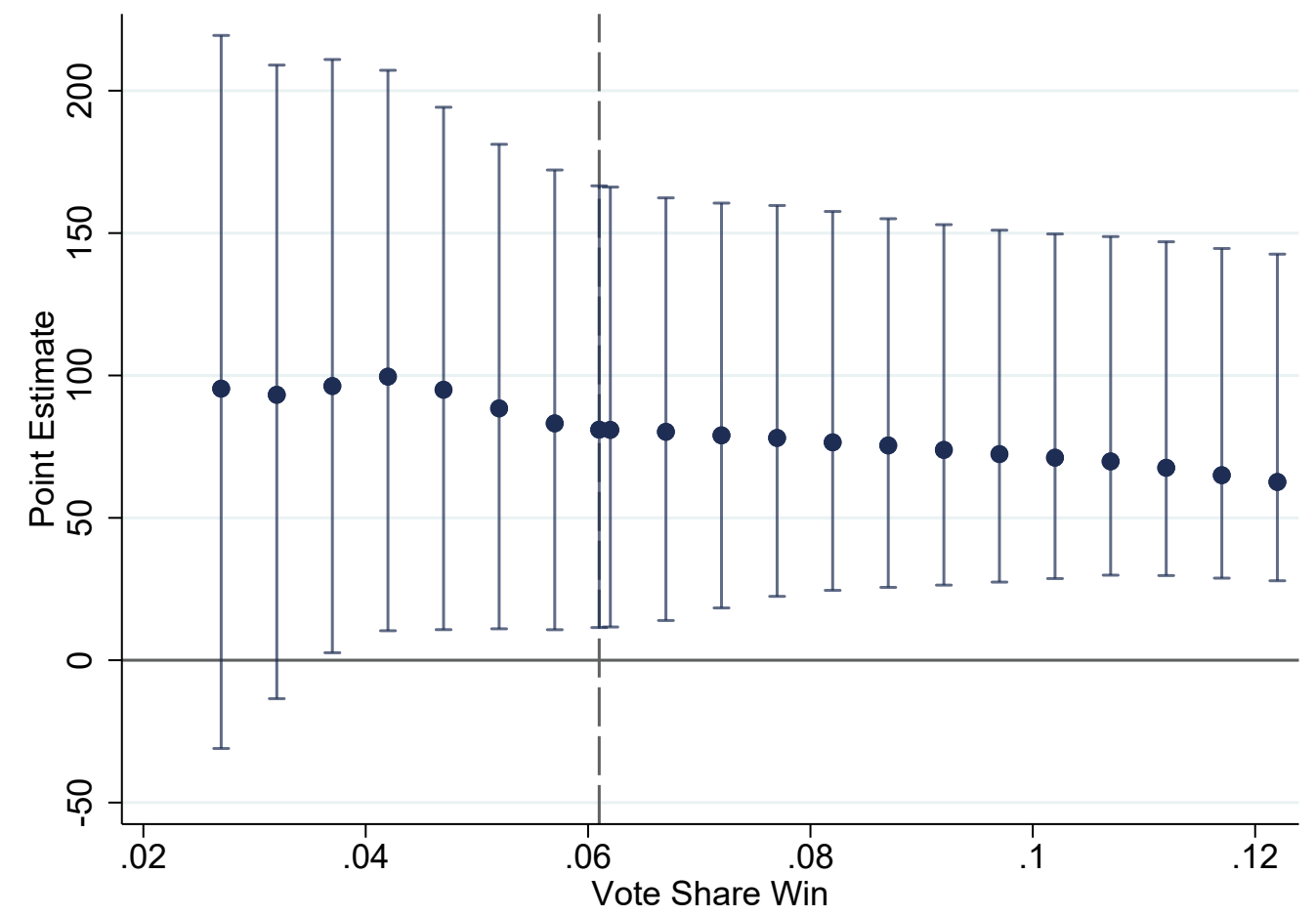

Note: Estimates of average treatment effects at the cut-off, using triangular kernel weights. Optimal MSE bandwidths displayed in the dotted line. Following Cattaneo, Idrobo and Titiunik (2020), we display estimates between half and double the optimal bandwidth. Robust $90 \%$ confidence intervals estimated following Calonico, Cattaneo and Titiunik (2014). 


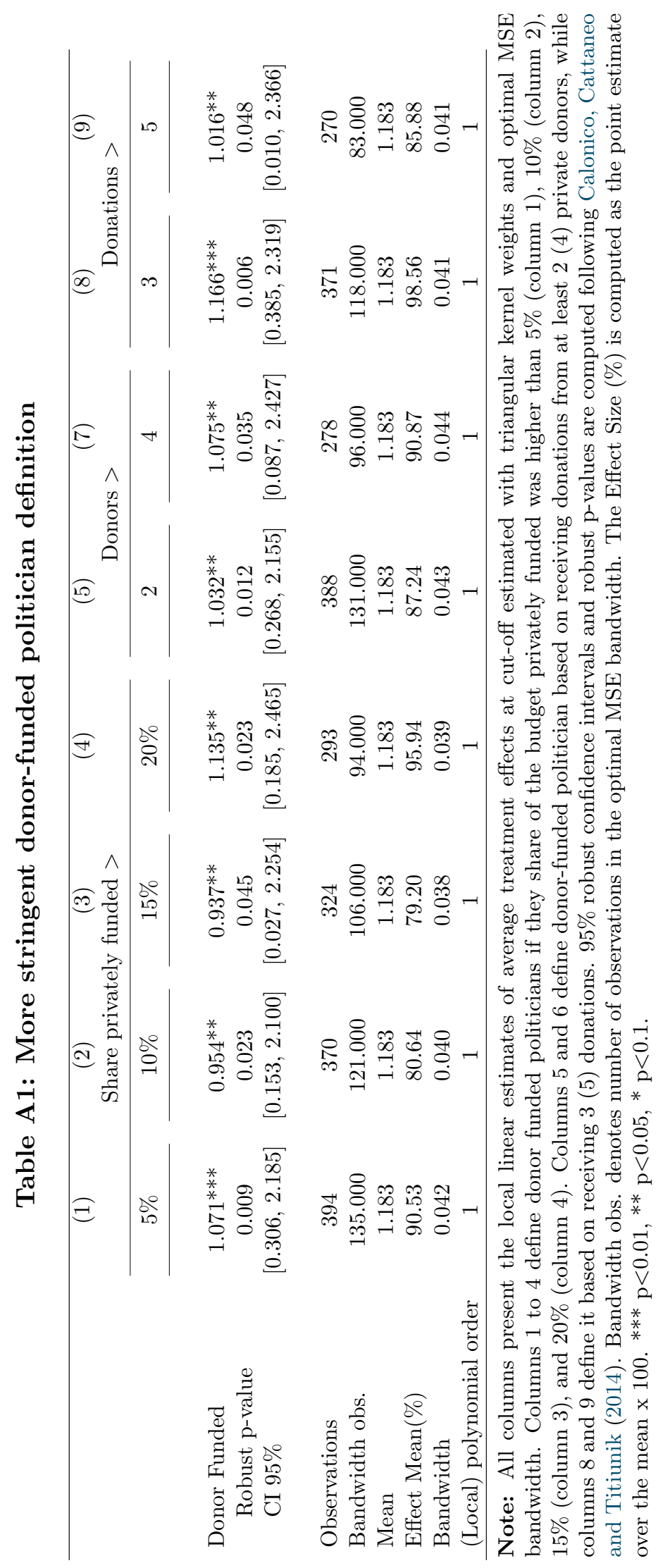


Table A2: Difference between RD sample and rest of the country

\begin{tabular}{|c|c|c|c|c|c|c|}
\hline \multirow[b]{4}{*}{ A. Individual covariates } & (1) & $(2)$ & $(3)$ & $(4)$ & $(5)$ & (6) \\
\hline & \multicolumn{2}{|c|}{ In sample } & \multicolumn{2}{|c|}{ Rest of the country } & \multirow{3}{*}{$\begin{array}{c}\text { p-value } \\
\text { difference }\end{array}$} & \multirow{3}{*}{$\begin{array}{c}\text { Standardized } \\
\text { difference }\end{array}$} \\
\hline & Mean & Std. Dev. & Mean & Std. Dev. & & \\
\hline & & & & & & \\
\hline Women & 0.136 & 0.344 & 0.093 & 0.290 & 0.115 & 0.137 \\
\hline Age & 43.492 & 9.328 & 45.057 & 9.782 & 0.092 & -0.164 \\
\hline Black & 0.079 & 0.271 & 0.041 & 0.199 & 0.057 & 0.160 \\
\hline Asian & 0.111 & 0.316 & 0.111 & 0.315 & 0.997 & -0.000 \\
\hline Left-wing party & 0.053 & 0.225 & 0.024 & 0.154 & 0.060 & 0.149 \\
\hline Right-wing party & 0.152 & 0.360 & 0.252 & 0.434 & 0.011 & -0.252 \\
\hline Illegal registration of ID. & 0.008 & 0.087 & 0.007 & 0.086 & 0.981 & 0.002 \\
\hline Has political experience & 0.348 & 0.478 & 0.371 & 0.483 & 0.621 & -0.046 \\
\hline \multicolumn{7}{|l|}{ B. Policy Outcomes } \\
\hline Total income Y(COP M) & $2.0 \mathrm{e}+04$ & $2.1 \mathrm{e}+04$ & $5.1 \mathrm{e}+04$ & $3.9 \mathrm{e}+05$ & 0.351 & -0.115 \\
\hline Land taxes $(\% \mathrm{Y})$ & 3.508 & 3.890 & 3.941 & 4.803 & 0.321 & -0.099 \\
\hline Industry $(\% \mathrm{Y})$ & 3.054 & 6.380 & 3.413 & 5.907 & 0.518 & -0.058 \\
\hline Funct. expen. (\%Y) & 13.030 & 5.259 & 13.316 & 5.006 & 0.541 & -0.056 \\
\hline Investment $(\% \mathrm{Y})$ & 86.970 & 5.259 & 86.684 & 5.006 & 0.541 & 0.056 \\
\hline Deficit $(\% \mathrm{Y})$ & 11.239 & 10.189 & 11.369 & 9.508 & 0.884 & -0.013 \\
\hline \multicolumn{7}{|c|}{ C. Other municipality socio-economic characteristics } \\
\hline Altitude (meter) & 960.114 & 899.361 & 1186.192 & 1193.095 & 0.036 & -0.214 \\
\hline Area in square km & 772.886 & 1488.967 & 892.197 & 3142.693 & 0.668 & -0.049 \\
\hline Distance to department capital & 84.502 & 54.130 & 77.844 & 56.357 & 0.202 & 0.121 \\
\hline Distance to Bogota & 338.659 & 201.668 & 316.599 & 187.932 & 0.211 & 0.113 \\
\hline Literacy rate & 83.997 & 7.463 & 83.881 & 8.631 & 0.883 & 0.014 \\
\hline Rurality index (0-1) & 0.539 & 0.219 & 0.567 & 0.242 & 0.201 & -0.123 \\
\hline Unsatisfied basic needs & 43.599 & 17.666 & 44.786 & 20.620 & 0.529 & -0.062 \\
\hline National Parks Area (1,000 sq. hct) & 0.568 & 2.838 & 0.974 & 8.070 & 0.566 & -0.067 \\
\hline CAR office & 0.136 & 0.344 & 0.143 & 0.351 & 0.827 & -0.020 \\
\hline Distance to CAR office & 0.033 & 0.028 & 0.029 & 0.033 & 0.260 & 0.111 \\
\hline Comptroller general offices & 0.053 & 0.334 & 0.695 & 6.890 & 0.285 & -0.132 \\
\hline Attorney general offices & 0.894 & 1.792 & 4.560 & 41.051 & 0.305 & -0.126 \\
\hline Paramilitary attacks & 1.394 & 7.212 & 1.271 & 10.141 & 0.893 & 0.014 \\
\hline Guerrilla attacks & 0.652 & 2.268 & 0.602 & 2.066 & 0.800 & 0.023 \\
\hline \multicolumn{7}{|l|}{ D. Other potential explanations } \\
\hline Deforestation during previous term & 2.359 & 2.046 & 2.110 & 2.019 & 0.185 & 0.122 \\
\hline Disposable Income (mw) & 6255.348 & $1.1 \mathrm{e}+04$ & $3.2 \mathrm{e}+04$ & $4.2 \mathrm{e}+05$ & 0.489 & -0.087 \\
\hline Municipal category & 5.902 & 0.460 & 5.679 & 1.048 & 0.016 & 0.275 \\
\hline Total population & $1.9 \mathrm{e}+04$ & $2.0 \mathrm{e}+04$ & $4.5 \mathrm{e}+04$ & $2.7 \mathrm{e}+05$ & 0.281 & -0.133 \\
\hline Income from royalties & 0.102 & 0.186 & 0.066 & 0.145 & 0.009 & 0.222 \\
\hline
\end{tabular}

Note: The first two columns present the basic statistics (mean and standard deviation) of each covariate for the regression discontinuity sample within the optimal bandwidth, while columns 3 and 4 present them for the rest of the country. Column 5 presents the p-value of the differences in means, while column 6 presents the standardized difference between the two groups. 


\section{Table A3: Donor funded politician and deforestation during term in office: Cubic}

polynomial

\begin{tabular}{lcc}
\hline & $(1)$ & $(2)$ \\
& \multicolumn{2}{c}{ Loc. Linear Pol-3 } \\
\hline Donor Funded & $1.326^{* *}$ & $0.989^{* *}$ \\
$\quad$ Robust p-value & 0.025 & 0.035 \\
CI 95\% & {$[0.164,2.477]$} & {$[0.071,1.903]$} \\
& & \\
Previous deforestation & & $\checkmark$ \\
& & \\
Observations & 408 & 408 \\
Bandwidth obs. & 274.000 & 274.000 \\
Mean & 1.183 & 1.183 \\
Effect Mean(\%) & 112.09 & 83.60 \\
Bandwidth & 0.100 & 0.101 \\
(Local) polynomial order & 3 & 3 \\
\hline
\end{tabular}

Note: Columns 1 and 2 present the cubic estimates of average treatment effects at cut-off estimated with triangular kernel weights and optimal MSE bandwidth. 95\% robust confidence intervals and robust p-values are computed following Calonico, Cattaneo and Titiunik (2014). Bandwidth obs. denotes number of observations in the optimal MSE bandwidth. The Effect Size (\%) is computed as the point estimate over the mean x 100 . Columns (2) and (4) include as covariate the measure of deforestation in the previous term (2008-2011). *** $\mathrm{p}<0.01,{ }^{* *} \mathrm{p}<0.05,{ }^{*} \mathrm{p}<0.1$. 
Table A4: Donor funded politician and deforestation: OLS

\begin{tabular}{|c|c|c|c|c|c|c|}
\hline Controls used: & $\begin{array}{c}(1) \\
\text { Baseline } \\
\text { (No controls) }\end{array}$ & $\begin{array}{c}(2) \\
\text { Pre-term } \\
\text { deforestation }\end{array}$ & $\begin{array}{c}(3) \\
\text { Politician } \\
\text { characteristics }\end{array}$ & $\begin{array}{c}\text { (4) } \\
\text { Development } \\
\text { characteristics }\end{array}$ & $\begin{array}{c}(5) \\
\text { Forest } \\
\text { coverage }\end{array}$ & $\begin{array}{c}(6) \\
\text { Agricultural } \\
\text { preasure }\end{array}$ \\
\hline Donor Funded & $\begin{array}{c}0.428^{* * *} \\
(0.095)\end{array}$ & $\begin{array}{c}0.266^{* * *} \\
(0.080)\end{array}$ & $\begin{array}{c}0.248^{* * *} \\
(0.081)\end{array}$ & $\begin{array}{c}0.222^{* *} \\
(0.089)\end{array}$ & $\begin{array}{c}0.257^{* * * *} \\
(0.080)\end{array}$ & $\begin{array}{c}0.276^{* * *} \\
(0.080)\end{array}$ \\
\hline Observations & 996 & 996 & 995 & 996 & 996 & 996 \\
\hline R-squared & 0.021 & 0.312 & 0.317 & 0.356 & 0.315 & 0.325 \\
\hline Mean DV & 1.182 & 1.182 & 1.182 & 1.182 & 1.182 & 1.182 \\
\hline
\end{tabular}

Note: OLS regression for deforestation in the mayor's term. Donor Funded is a dummy that takes the value one if the mayor was donor funded. Column 2 to 6 add as control deforestation in the pre-electoral period. Column 3 adds as controls politician characteristics such as political ideology, political experience, and previous electoral illegal behavior. Column 4 adds municipality characteristics such as population density, rural population, and nighttime lights. Column 5 adds forest coverage. Column 6 adds the total agricultural production and the hectares use for agricultural production. Robust standard errors are presented in parenthesis. $* * * \mathrm{p}<0.01, * *$ $\mathrm{p}<0.05,{ }^{*} \mathrm{p}<0.1$. 


\section{Table A5: Donor funded politician and deforestation ratio - Quadratic Polynomial}

\begin{tabular}{|c|c|c|c|c|}
\hline & (1) & $(2)$ & $(3)$ & (4) \\
\hline & \multicolumn{4}{|c|}{ Year of government } \\
\hline & 1 & 2 & 3 & 4 \\
\hline Donor Funded & $0.002^{* * *}$ & $0.002^{*}$ & 0.002 & $0.005^{* *}$ \\
\hline Robust p-value & 0.009 & 0.074 & 0.166 & 0.048 \\
\hline CI $95 \%$ & {$[0.001,0.004]$} & {$[-0.000,0.005]$} & {$[-0.001,0.006]$} & {$[0.000,0.009]$} \\
\hline Observations & 408 & 408 & 408 & 408 \\
\hline Bandwidth obs. & 188 & 200 & 209 & 187 \\
\hline Mean & 0.012 & 0.012 & 0.012 & 0.012 \\
\hline Effect size $(\%)$ & 16.67 & 16.67 & 16.67 & 41.67 \\
\hline Bandwidth & 0.059 & 0.066 & 0.070 & 0.059 \\
\hline (Local) polynomial order & 2 & 2 & 2 & 2 \\
\hline
\end{tabular}

Note: Local quadratic estimates of average treatment effects at cut-off estimated with triangular kernel weights and optimal MSE bandwidth. 95\% robust confidence intervals and robust p-values are computed following Calonico, Cattaneo and Titiunik (2014). Bandwidth obs. denotes number of observations in the optimal MSE bandwidth. Each column shows the deforestation rate, defined as lost coverage $_{t} /$ coverage $_{\text {election year }}$, for a given year of government. The Effect size $(\%)$ is computed as the point estimate over the mean $\mathrm{x} 100 .{ }^{* * *} \mathrm{p}<0.01, * *$ $\mathrm{p}<0.05,{ }^{*} \mathrm{p}<0.1$. 
Table A6: Donor funded politician and contracts: Quadratic polynomial

\begin{tabular}{|c|c|c|c|c|c|c|c|}
\hline & (1) & $(2)$ & $(3)$ & (4) & $(5)$ & $(6)$ & $(7)$ \\
\hline & \multicolumn{3}{|c|}{ Infrastructure } & \multicolumn{2}{|c|}{ Environmental } & \multicolumn{2}{|c|}{ Mining } \\
\hline & Number & Log Avg. value & $\begin{array}{c}\text { Road } \\
\text { construction }\end{array}$ & Number & Log Avg. value & Number & Log Avg. value \\
\hline Donor Funded & -54.930 & $1.206^{* *}$ & -0.013 & -20.619 & 0.502 & 0.278 & 1.592 \\
\hline Robust p-value & 0.373 & 0.021 & 0.646 & 0.446 & 0.293 & 0.598 & 0.111 \\
\hline CI $95 \%$ & {$[-204.554,76.718]$} & {$[0.190,2.374]$} & {$[-0.051,0.032]$} & {$[-101.749,44.742]$} & {$[-0.418,1.385]$} & {$[-0.895,1.553]$} & {$[-0.451,4.344]$} \\
\hline Observations & 401 & 400 & 406 & 401 & 366 & 401 & 145 \\
\hline Bandwidth obs. & 227 & 246 & 252 & 229 & 205 & 268 & 66 \\
\hline Mean & 140.896 & 4.818 & 0.013 & 18.197 & 3.795 & 0.976 & 3.618 \\
\hline Effect Mean $(\%)$ & -38.99 & 120 & -86.67 & -113.31 & 50 & 28.48 & 159 \\
\hline Bandwidth & 0.077 & 0.089 & 0.074 & 0.080 & 0.076 & 0.101 & 0.067 \\
\hline (Local) polynomial order & 2 & 2 & 2 & 2 & 2 & 2 & 2 \\
\hline
\end{tabular}

Note: Local linear estimates of average treatment effects at cut-off estimated with triangular kernel weights and optimal MSE bandwidth. 95\% robust confidence intervals and robust p-values are computed following Calonico, Cattaneo and Titiunik (2014). Bandwidth obs. denotes number of observations in the optimal MSE bandwidth. The average value of contracts was transformed using inverse hyperbolic sine. The contracts are catalogued in each category by analysing their reported object. For columns 1,3 , 4, and 6 , the effect size (\%) is computed as the point estimate over the mean $\mathrm{x} 100$, while for the rest of the columns is the point estimate $\mathrm{x} 100$. $* * * \mathrm{p}<0.01$, $* * \mathrm{p}<0.05, * \mathrm{p}<0.1$. 
Table A7: Donor funded politician and avg. value of infrastructure contracts per year

\begin{tabular}{|c|c|c|c|c|}
\hline & \multicolumn{4}{|c|}{ Year of government } \\
\hline & 1 & 2 & 3 & 4 \\
\hline Donor Funded & 0.520 & 0.484 & $1.391^{* * *}$ & 0.760 \\
\hline Robust p-value & 0.245 & 0.252 & 0.008 & 0.116 \\
\hline CI $95 \%$ & {$[-0.410,1.610]$} & {$[-0.404,1.538]$} & {$[0.385,2.597]$} & {$[-0.217,1.968]$} \\
\hline Observations & 381 & 386 & 386 & 389 \\
\hline Bandwidth obs. & 179 & 195 & 193 & 179 \\
\hline Mean & 4.204 & 5.092 & 5.284 & 5.508 \\
\hline Effect size (\%) & 52 & 48 & 139 & 76 \\
\hline Bandwidth & 0.060 & 0.070 & 0.068 & 0.058 \\
\hline (Local) polynomial order & 1 & 1 & 1 & 1 \\
\hline
\end{tabular}

Note: Local linear estimates of average treatment effects at cut-off estimated with triangular kernel weights and optimal MSE bandwidth. 95\% robust confidence intervals and robust p-values are computed following Calonico, Cattaneo and Titiunik (2014). Bandwidth obs. denotes number of observations in the optimal MSE bandwidth. The average value of contracts was transformed using inverse hyperbolic sine. The contracts are catalogued in each category by analysing their reported object. The effect size (\%) is computed as the point estimate $\mathrm{x} 100$. ${ }^{* * *} \mathrm{p}<0.01,{ }^{* *} \mathrm{p}<0.05,{ }^{*} \mathrm{p}<0.1$. 


\section{Table A8: Donor funded politician and infrastructure contracts by relation to deforestation}

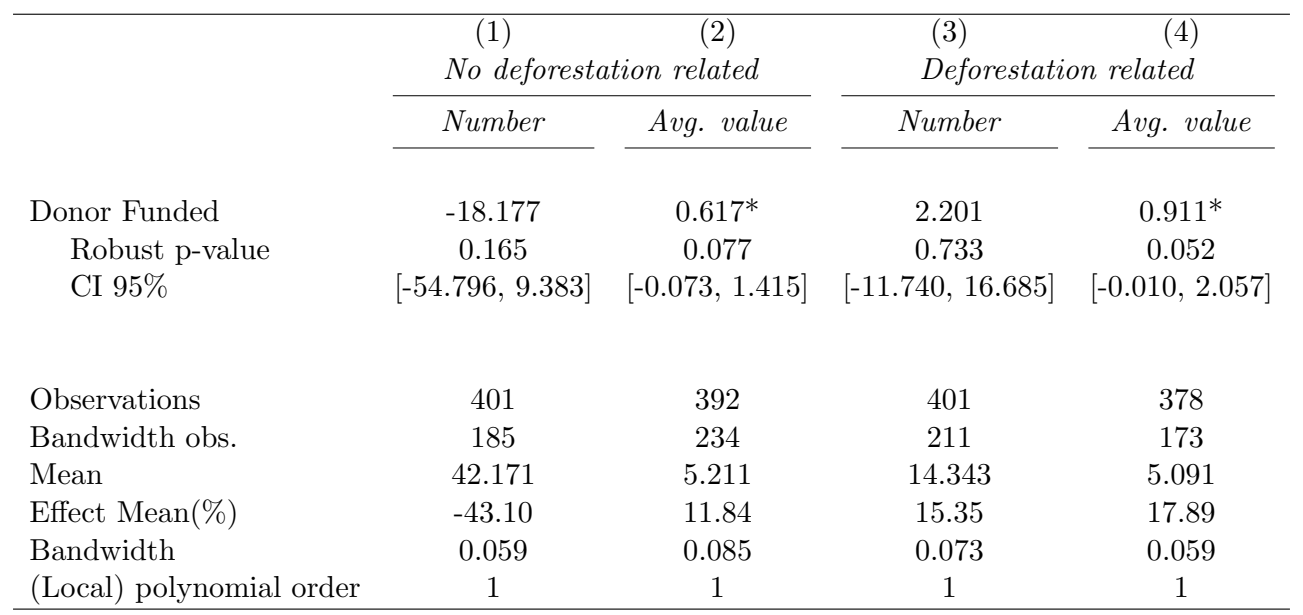

Note: Local linear estimates of average treatment effects at cut-off estimated with triangular kernel weights and optimal MSE bandwidth. 95\% robust confidence intervals and robust p-values are computed following Calonico, Cattaneo and Titiunik (2014). Bandwidth obs. denotes number of observations in the optimal MSE bandwidth. The average value of contracts was transformed using inverse hyperbolic sine. The contracts are catalogued in each category by analysing their reported object. The Effect size (\%) is computed as the point estimate over the mean $\mathrm{x} 100 .{ }^{* * *} \mathrm{p}<0.01,{ }^{* *} \mathrm{p}<0.05,{ }^{*} \mathrm{p}<0.1$. 
Table A9: Heterogeneous Effects: Armed Conflict - Quadratic Polynomial

\begin{tabular}{|c|c|c|c|}
\hline & $(1)$ & $(2)$ \\
\hline & & \multicolumn{2}{|c|}{ Measure Z } \\
\hline & & \multicolumn{2}{|c|}{ Attacks } \\
\hline & & Paramilitary & Guerrilla \\
\hline \multirow[t]{4}{*}{ A } & Donor funded & 0.337 & $0.733^{* *}$ \\
\hline & & $(0.364)$ & $(0.367)$ \\
\hline & $\mathrm{Z}$ & -0.0783 & $0.435^{*}$ \\
\hline & & $(0.144)$ & $(0.227)$ \\
\hline \multirow[t]{2}{*}{ B } & $\mathrm{Z} \times$ Donor funded & 0.168 & $-0.554^{* *}$ \\
\hline & & $(0.156)$ & $(0.241)$ \\
\hline \multicolumn{2}{|c|}{ Observations } & 408 & 408 \\
\hline \multicolumn{2}{|c|}{ Bandwidth obs. } & 191 & 191 \\
\hline \multicolumn{2}{|c|}{ R-squared } & 0.108 & 0.166 \\
\hline \multicolumn{2}{|c|}{ Bandwidth } & 0.0600 & 0.0600 \\
\hline \multicolumn{2}{|c|}{ (Local) polynomial order } & 2 & 2 \\
\hline \multicolumn{2}{|c|}{$\mathrm{A}+\mathrm{B}$} & 0.505 & 0.179 \\
\hline \multicolumn{2}{|c|}{ Effect size } & 30.50 & 8.68 \\
\hline \multicolumn{4}{|c|}{ Ho: $A+B=0$} \\
\hline \multicolumn{2}{|c|}{ F-statistic } & 2.43 & 0.21 \\
\hline \multicolumn{2}{|c|}{$\mathrm{P}$-value } & 0.12 & 0.64 \\
\hline
\end{tabular}

Note: OLS regression weighted by a triangular kernel within the MSE optimal bandwidth sample and controlling for a quadratic polynomial. Bandwidth obs. denotes number of observations in the optimal MSE bandwidth. The dependent variable is deforestation during the full term. Paramilitary (Guerrilla) attacks is the number of paramilitary (guerrilla) attacks during the previous term (2008-2011). The Effect size (\%) is computed as $100 x(A+B) /\left(\right.$ constant $\left.+\beta_{Z}\right)$. *** $\mathrm{p}<0.01,{ }^{* *} \mathrm{p}<0.05,{ }^{*} \mathrm{p}<0.1$. 


\section{Table A10: Donor funded politician and fire intensity - Quadratic polynomial}

Donor Funded

Robust p-value

CI $95 \%$

Previous intensity

Observations

Bandwidth obs.

Mean

Effect size $(\%)$

Bandwidth

(Local) polynomial order

\section{(1)}

$$
92.839^{* *}
$$

0.044

[2.659, 187.461]

(2)

77.625

0.145

[-26.568, 180.535]

408

312

246.141

37.72

0.124
$\checkmark$
408
217
246.141
31.54
0.073

Note: Local quadratic estimates of average treatment effects at cut-off estimated with triangular kernel weights and optimal MSE bandwidth. 95\% robust confidence intervals and robust p-values are computed following Calonico, Cattaneo and Titiunik (2014). Bandwidth obs. denotes number of observations in the optimal MSE bandwidth. Column (2) includes as covariate the measure of fire intensity from the previous term (2009-2011), being 2009 the first year with data availability. Fire intensity is measured as the average brightness of fires in a municipality. The Effect size (\%) is computed as the point estimate over the mean $\mathrm{x} 100 . * * * \mathrm{p}<0.01, * * \mathrm{p}<0.05$, $* \mathrm{p}<0.1$. 


\section{Table A11: Donor funded politician and fire intensity by year of government}

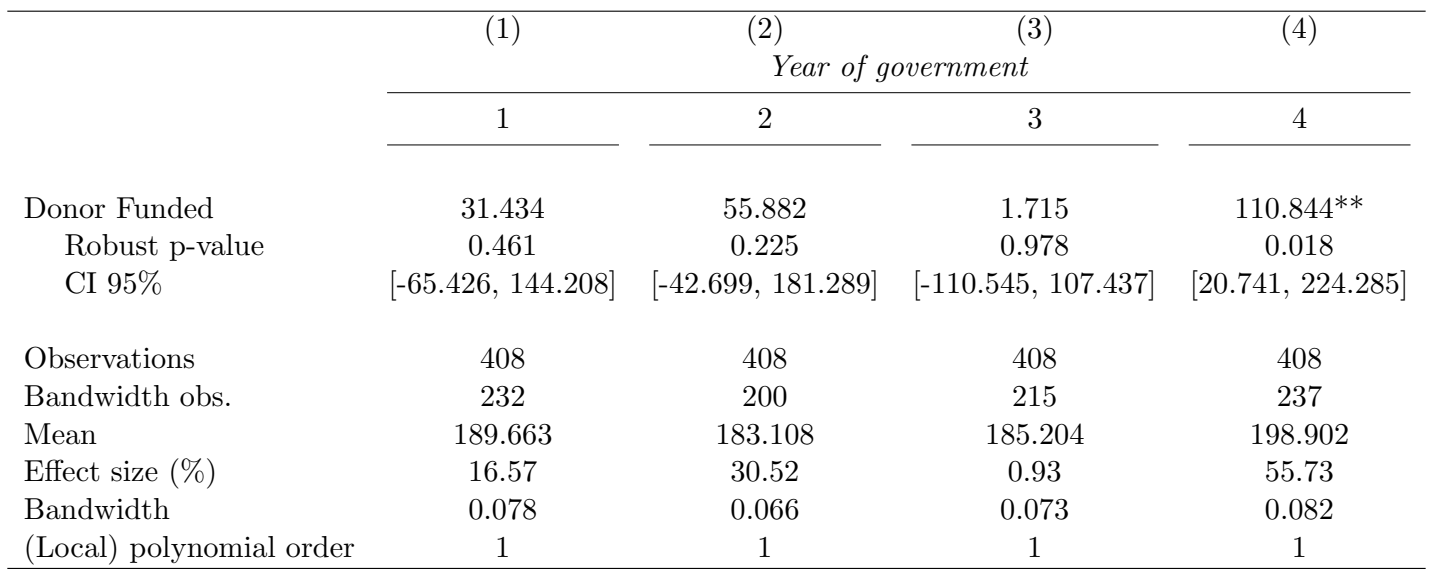

Note: Local linear estimates of average treatment effects at cut-off estimated with triangular kernel weights and optimal MSE bandwidth. 95\% robust confidence intervals and robust p-values are computed following Calonico, Cattaneo and Titiunik (2014). Bandwidth obs. denotes number of observations in the optimal MSE bandwidth. Fire intensity is measured as the average brightness of fires in a municipality. The Effect size (\%) is computed as the point estimate over the mean $\mathrm{x} 100$. ${ }^{* * *} \mathrm{p}<0.01,{ }^{*} * \mathrm{p}<0.05,{ }^{*} \mathrm{p}<0.1$. 
Table A12: Donor funded politician and agro-cattle firms entry by year

\begin{tabular}{|c|c|c|c|c|}
\hline & \multicolumn{4}{|c|}{ Year of government } \\
\hline & 1 & 2 & 3 & 4 \\
\hline Donor Funded & 1.093 & 1.831 & 1.340 & $2.569^{* *}$ \\
\hline Robust p-value & 0.314 & 0.243 & 0.496 & 0.019 \\
\hline CI $95 \%$ & {$[-1.151,3.585]$} & {$[-1.308,5.169]$} & {$[-1.893,3.910]$} & {$[0.495,5.653]$} \\
\hline Observations & 408 & 408 & 408 & 408 \\
\hline Bandwidth obs. & 190 & 198 & 232 & 161 \\
\hline Mean & 0.211 & 0.306 & 0.211 & 0.455 \\
\hline Effect size (\%) & 518.01 & 598.37 & 635.07 & 564.62 \\
\hline Bandwidth & 0.060 & 0.063 & 0.077 & 0.048 \\
\hline (Local) polynomial order & 1 & 1 & 1 & 1 \\
\hline
\end{tabular}

Note: Local linear estimates of average treatment effects at cut-off estimated with triangular kernel weights and optimal MSE bandwidth. 95\% robust confidence intervals and robust p-values are computed following Calonico, Cattaneo and Titiunik (2014). Bandwidth obs. denotes number of observations in the optimal MSE bandwidth. The dependent variable is the number of firms registered in agro-cattle business during that year. The Effect Size $(\%)$ is computed as the point estimate over the mean $\mathrm{x} 100 .{ }^{* * *} \mathrm{p}<0.01,{ }^{* *} \mathrm{p}<0.05,{ }^{*} \mathrm{p}<0.1$. 
Table A13: Donor funded politician and agro-cattle firms entry by year - Quadratic

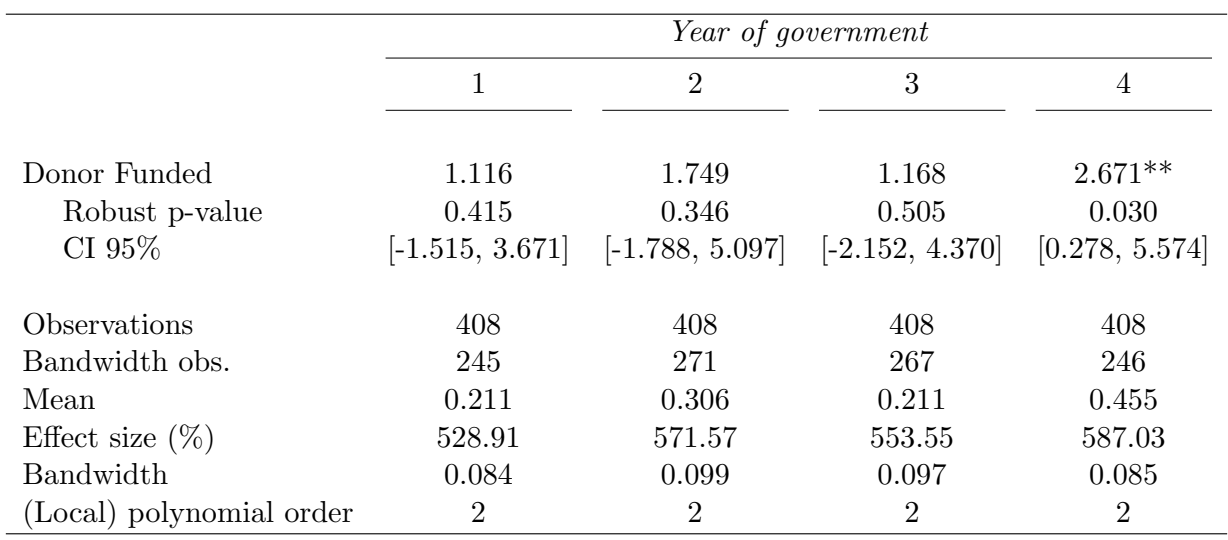

Note: Local quadratic estimates of average treatment effects at cut-off estimated with triangular kernel weights and optimal MSE bandwidth. 95\% robust confidence intervals and robust p-values are computed following Calonico, Cattaneo and Titiunik (2014). Bandwidth obs. denotes number of observations in the optimal MSE bandwidth. The dependent variable is the number of firms registered in agro-cattle business during that year. The Effect Size (\%) is computed as the point estimate over the mean x 100. ${ }^{* * *} \mathrm{p}<0.01,{ }^{* *} \mathrm{p}<0.05,{ }^{*} \mathrm{p}<0.1$. 


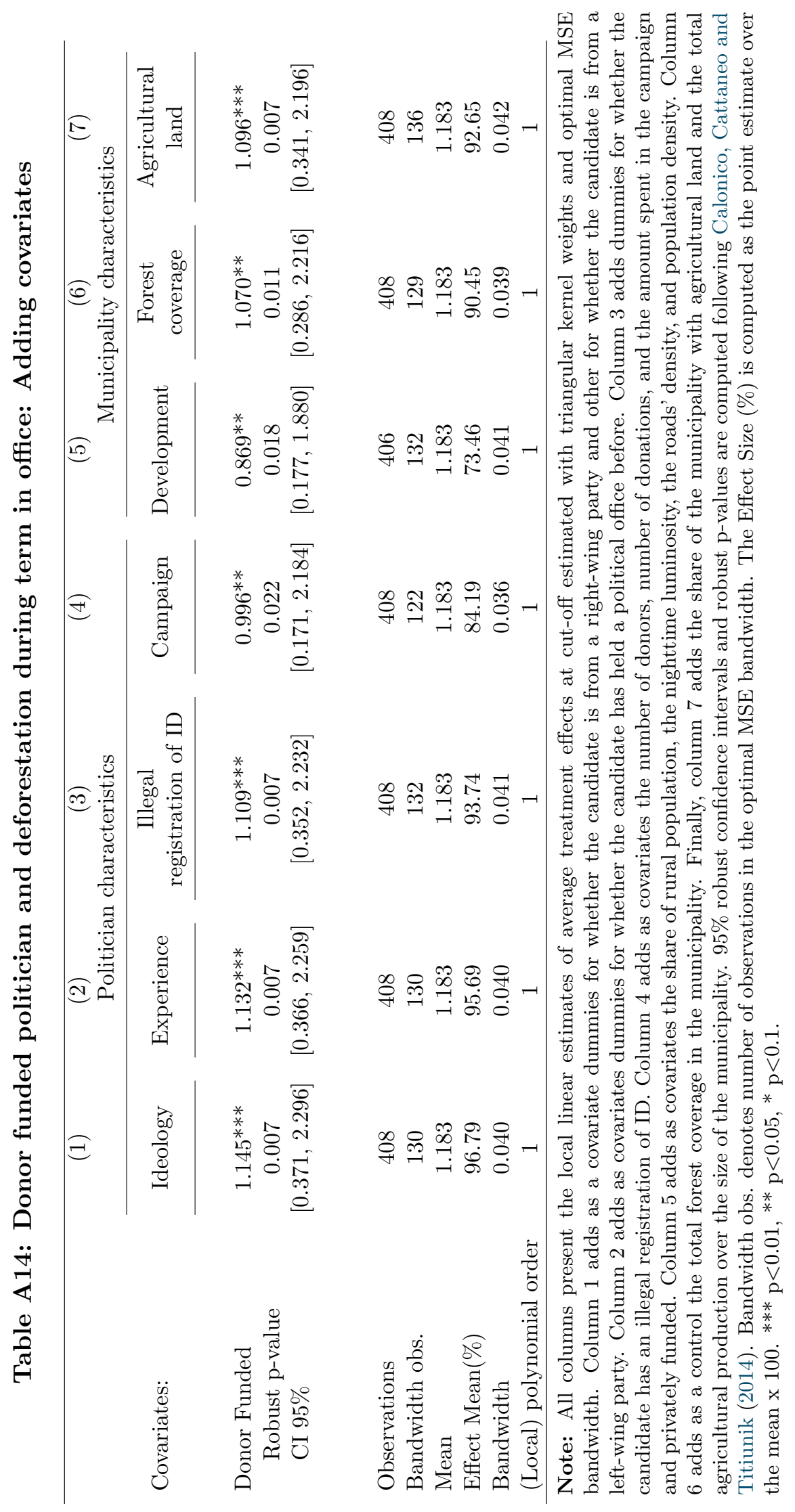


Table A15: Heterogeneous effects by state presence controlling for agricultural pressure

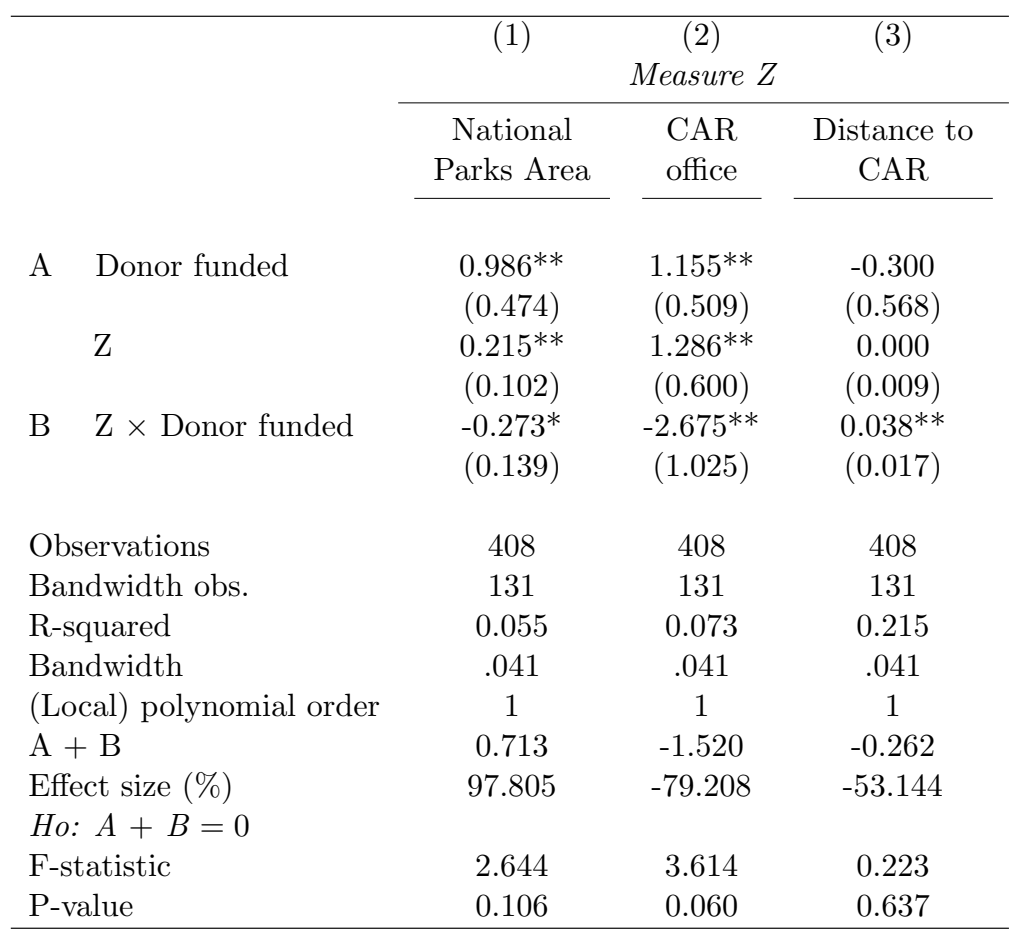

Note: OLS regression weighted by a triangular kernel within the MSE optimal bandwidth sample and controlling for a linear polynomial. Bandwidth obs. denotes number of observations in the optimal MSE bandwidth. The dependent variable is deforestation during the full term. National Parks area is defined as the total area with national parks in the municipality, CAR office is a dummy that takes the value one if there was at least on CAR office in the municipality, and Distance to CAR is the distance to the closest CAR. All specifications control for the share of of the municipality with agricultural land and total agricultural production over the size of the municipality. The Effect size $(\%)$ is computed as $100 x(A+B) /\left(\right.$ constant $\left.+\beta_{Z}\right)$. ${ }^{* * *} \mathrm{p}<0.01,{ }^{* *} \mathrm{p}<0.05,{ }^{*} \mathrm{p}<0.1$. 
Table A16: Donor funded politician and deforestation during term in office: Using different weights

\begin{tabular}{lccc}
\hline \multirow{2}{*}{ Weights } & $\begin{array}{c}(1) \\
\text { Forest } \\
\text { coverage }\end{array}$ & & $\begin{array}{c}(2) \\
\text { Municipality } \\
\text { area }\end{array}$ \\
\cline { 2 - 2 } Donor funded & & \\
& $\begin{array}{c}1.311^{* *} \\
(0.564)\end{array}$ & & $1.164^{* *}$ \\
Observations & & & \\
Bandwidth obs. & 408 & & 408 \\
R-squared & 132 & & 132 \\
Bandwidth & 0.157 & & 0.139 \\
(Local) polynomial order & .041 & & .041 \\
\hline
\end{tabular}

Note: OLS regression within the MSE optimal bandwidth sample and controlling for a linear polynomial. In column 1, we weight the observations using the forest coverage in the municipality in 2011, while in column 2 , we use the area of the municipality as weight. Bandwidth obs. denotes number of observations in the optimal MSE bandwidth. ${ }^{* * *} \mathrm{p}<0.01,{ }^{* *} \mathrm{p}<0.05,{ }^{*} \mathrm{p}<0.1$. 
Table A17: Heterogeneous effects by agricultural presence

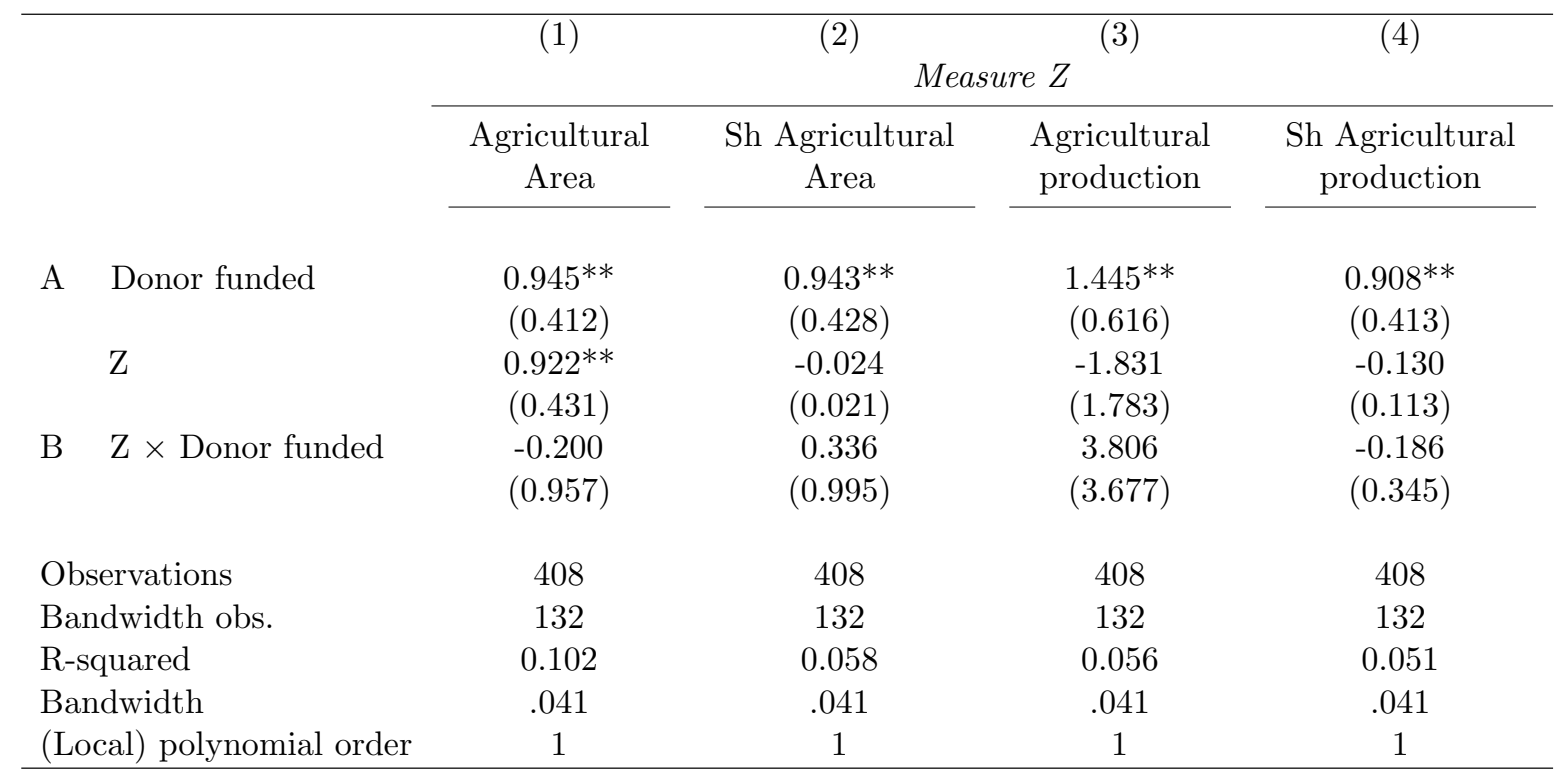

Note: OLS regression weighted by a triangular kernel within the MSE optimal bandwidth sample and controlling for a quadratic polynomial. The variables used for heterogeneous effects $(Z)$ are: the total agricultural area, the share of the municipality with agricultural area, total agricultural production, and the share of total agricultural production over the size of the municipality. In all cases, we standardize the $Z$ variable by it's average and standard deviation. Bandwidth obs. denotes number of observations in the optimal MSE bandwidth. $* * *$ $\mathrm{p}<0.01$, ** $\mathrm{p}<0.05, * \mathrm{p}<0.1$. 
Table A18: Right-wing politician and deforestation during term in office

\begin{tabular}{lcccc}
\hline & $(1)$ & $(2)$ & $(3)$ & $(4)$ \\
& \multicolumn{2}{c}{ Loc. Linear Pol-1 } & \multicolumn{2}{c}{ Loc. Linear Pol-2 } \\
\hline Right-wing Politician & 0.101 & 0.059 & 0.126 & -0.131 \\
$\quad$ Robust p-value & 0.805 & 0.966 & 0.786 & 0.607 \\
CI 95\% & {$[-0.815,1.050]$} & {$[-0.648,0.620]$} & {$[-0.912,1.205]$} & {$[-0.977,0.570]$} \\
& & & & \\
Previous deforestation & & $\checkmark$ & & $\checkmark$ \\
& & & 482 & 482 \\
Observations & 482 & 482 & 349 & 294 \\
Bandwidth obs. & 264 & 245 & 1.183 & 1.183 \\
Mean & 1.183 & 1.183 & 10.65 & -11.07 \\
Effect Mean(\%) & 8.54 & 4.99 & 0.121 & 0.096 \\
Bandwidth & 0.081 & 0.073 & 2 & 2 \\
(Local) polynomial order & 1 & 1 & & \\
\hline
\end{tabular}

Note: Columns 1 and 2 present the local linear estimates of average treatment effects at cut-off estimated with triangular kernel weights and optimal MSE bandwidth. Columns 3 and 4 presents the quadratic estimates of average treatment effects at cut-off estimated with triangular kernel weights and optimal MSE bandwidth. 95\% robust confidence intervals and robust p-values are computed following Calonico, Cattaneo and Titiunik (2014). Bandwidth obs. denotes number of observations in the optimal MSE bandwidth. The Effect Size (\%) is computed as the point estimate over the mean $\mathrm{x} 100$. Columns (2) and (4) include as covariate the measure of deforestation in the previous term $(2008-2011)$. ${ }^{* * *} \mathrm{p}<0.01,{ }^{* *} \mathrm{p}<0.05,{ }^{*} \mathrm{p}<0.1$. 
Table A19: Heterogeneous effects by candidate characteristics

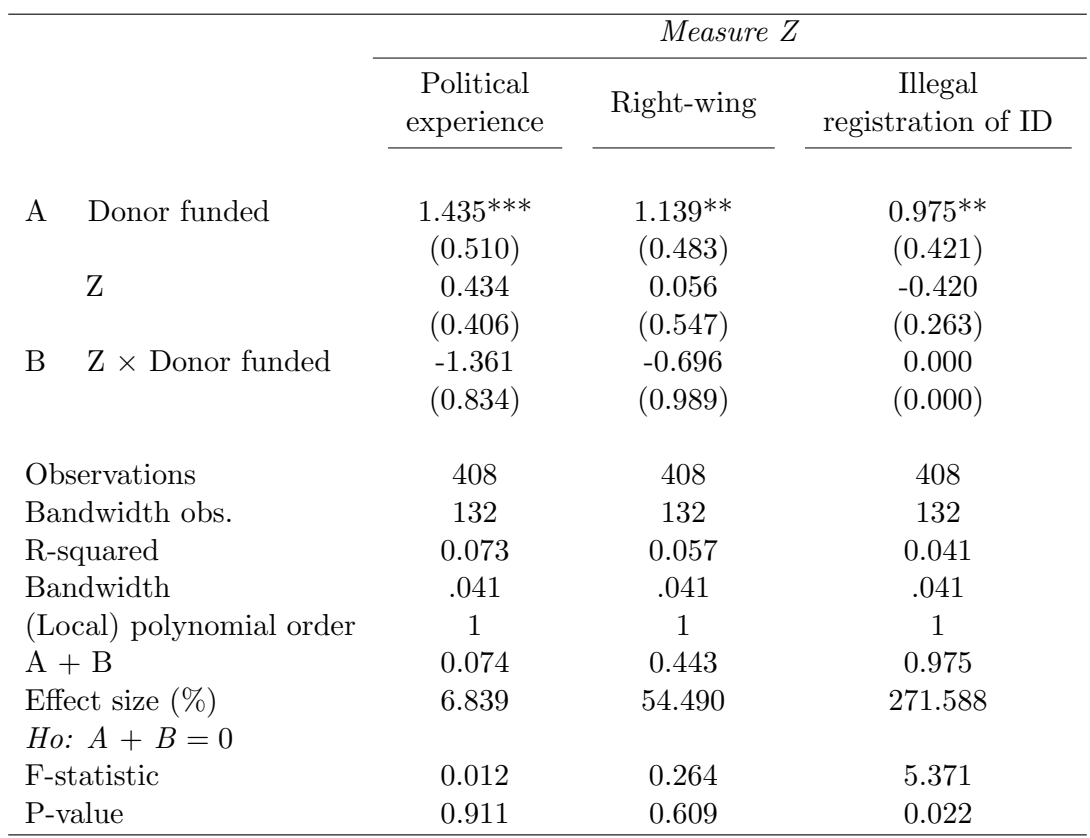

Note: OLS regression weighted by a triangular kernel within the MSE optimal bandwidth sample and controlling for a linear polynomial. Bandwidth obs. denotes number of observations in the optimal MSE bandwidth. The dependent variable is deforestation during the full term. Political experience is a dummy for whether the candidate has held political office previously. Right-wing is a dummy for the candidate being from a right-wing party. Illegal registration of ID is a dummy for whether the candidate had an illegal registration of an ID. Bandwidth obs. denotes number of observations in the optimal MSE bandwidth. ${ }^{* * *} \mathrm{p}<0.01,{ }^{* *} \mathrm{p}<0.05,{ }^{*} \mathrm{p}<0.1$. 
Table A20: Politically experienced politician and deforestation during term in office

\begin{tabular}{lcccc}
\hline & $(1)$ & $(2)$ & $(3)$ & $(4)$ \\
& \multicolumn{2}{c}{ Loc. Linear Pol-1 } & \multicolumn{2}{c}{ Loc. Linear Pol-2 } \\
\hline & & & & \\
Politically Experienced & 0.154 & 0.102 & -0.010 & 0.034 \\
$\quad$ Robust p-value & 0.544 & 0.891 & 0.820 & 0.873 \\
CI 95\% & {$[-0.535,1.016]$} & {$[-0.680,0.782]$} & {$[-1.175,0.931]$} & {$[-0.883,0.749]$} \\
& & & & \\
Previous deforestation & & $\checkmark$ & & $\checkmark$ \\
& & & 479 & 479 \\
Observations & 479 & 479 & 275 & 291 \\
Bandwidth obs. & 282 & 221 & 1.183 & 1.183 \\
Mean & 1.183 & 1.183 & -0.84 & 2.87 \\
Effect Mean(\%) & 13.02 & 8.62 & 0.081 & 0.091 \\
Bandwidth & 0.084 & 0.065 & 2 & 2 \\
(Local) polynomial order & 1 & 1 & & \\
\hline
\end{tabular}

Note: Columns 1 and 2 present the local linear estimates of average treatment effects at cut-off estimated with triangular kernel weights and optimal MSE bandwidth. Columns 3 and 4 presents the quadratic estimates of average treatment effects at cut-off estimated with triangular kernel weights and optimal MSE bandwidth. 95\% robust confidence intervals and robust p-values are computed following Calonico, Cattaneo and Titiunik (2014). Bandwidth obs. denotes number of observations in the optimal MSE bandwidth. The Effect Size (\%) is computed as the point estimate over the mean $\mathrm{x} 100$. Columns (2) and (4) include as covariate the measure of deforestation in the previous term $(2008-2011)$. ${ }^{* * *} \mathrm{p}<0.01,{ }^{* *} \mathrm{p}<0.05,{ }^{*} \mathrm{p}<0.1$. 


\section{Table A21: Heterogeneous Effects: State Presence - Quadratic Polynomial}

\begin{tabular}{|c|c|c|c|c|c|c|}
\hline & & \multicolumn{5}{|c|}{ Measure Z } \\
\hline & & $\begin{array}{c}\text { National } \\
\text { Parks Area }\end{array}$ & $\begin{array}{l}\text { CAR } \\
\text { office }\end{array}$ & $\begin{array}{c}\text { Distance to } \\
\text { CAR }\end{array}$ & $\begin{array}{c}\text { Procurator } \\
\text { offices }\end{array}$ & $\begin{array}{c}\text { Attorney } \\
\text { offices }\end{array}$ \\
\hline \multirow[t]{2}{*}{ A } & Donor funded & $\begin{array}{l}0.679^{*} \\
(0.366)\end{array}$ & $\begin{array}{l}0.750^{*} \\
(0.386)\end{array}$ & $\begin{array}{c}-0.234 \\
(0.429)\end{array}$ & $\begin{array}{c}0.624^{*} \\
(0.361)\end{array}$ & $\begin{array}{c}0.830^{* *} \\
(0.405)\end{array}$ \\
\hline & $\mathrm{Z}$ & $\begin{array}{c}0.348 \\
(0.240)\end{array}$ & $\begin{array}{c}1.532^{*} \\
(0.798)\end{array}$ & $\begin{array}{r}-0.00279 \\
(0.0101)\end{array}$ & $\begin{array}{c}1.062^{* * * *} \\
(0.310)\end{array}$ & $\begin{array}{r}-0.0685 \\
(0.143)\end{array}$ \\
\hline B & $\mathrm{Z} \times$ Donor funded & $\begin{array}{c}-0.329^{*} \\
(0.176)\end{array}$ & $\begin{array}{c}-2.072^{* * *} \\
(0.660)\end{array}$ & $\begin{array}{c}0.0267 * * \\
(0.0133)\end{array}$ & $\begin{array}{c}-1.695^{* * *} \\
(0.574)\end{array}$ & $\begin{array}{c}-0.285^{* *} \\
(0.118)\end{array}$ \\
\hline \multicolumn{2}{|c|}{ Observations } & 408 & 408 & 408 & 408 & 408 \\
\hline \multicolumn{2}{|c|}{ Bandwidth obs. } & 191 & 191 & 191 & 191 & 191 \\
\hline \multicolumn{2}{|c|}{ R-squared } & 0.069 & 0.083 & 0.201 & 0.068 & 0.087 \\
\hline \multicolumn{2}{|c|}{ Bandwidth } & 0.060 & 0.060 & 0.060 & 0.060 & 0.060 \\
\hline \multicolumn{2}{|c|}{ (Local) polynomial order } & 2 & 2 & 2 & 2 & 2 \\
\hline \multicolumn{2}{|c|}{$\mathrm{A}+\mathrm{B}$} & 0.350 & -1.322 & -0.207 & -1.071 & 0.545 \\
\hline \multicolumn{2}{|c|}{ Effect size (\%) } & 17.56 & -41.28 & -12.05 & -38.988 & 30.569 \\
\hline \multicolumn{7}{|c|}{ Ho: $A+B=0$} \\
\hline \multicolumn{2}{|c|}{ F-statistic } & .99 & 6.09 & 0.24 & 3.83 & 4.7 \\
\hline \multicolumn{2}{|c|}{ P-value } & 0.32 & 0.01 & 0.62 & 0.05 & 0.11 \\
\hline
\end{tabular}

Note: OLS regression weighted by a triangular kernel within the MSE optimal bandwidth sample and controlling for a quadratic polynomial. Bandwidth obs. denotes number of observations in the optimal MSE bandwidth. The dependent variable is deforestation during the full term. National Parks area is defined as the total area with national parks in the municipality, CAR office is a dummy that takes the value one if there was at least on CAR office in the municipality, Distance to CAR is the distance to the closest CAR, Comptroller offices is the number of offices of the Comptroller General (Procuraduría), and Attorney offices is the number of offices of the Attorney General (Fiscalía). The Effect size (\%) is computed as $100 x(A+B) /\left(\right.$ constant $\left.+\beta_{Z}\right)$. ${ }^{* * *} \mathrm{p}<0.01,{ }^{* *}$ $\mathrm{p}<0.05,{ }^{*} \mathrm{p}<0.1$. 


\section{Table A22: Donor funded politician and infrastructure contracts by year of}

government - Quadratic polynomial

\begin{tabular}{|c|c|c|c|c|}
\hline & \multicolumn{4}{|c|}{ Year of government } \\
\hline & 1 & 2 & 3 & 4 \\
\hline Donor Funded & 0.561 & 0.195 & $1.431^{* *}$ & 0.886 \\
\hline Robust p-value & 0.418 & 0.918 & 0.028 & 0.114 \\
\hline CI $95 \%$ & {$[-0.752,1.812]$} & {$[-1.209,1.344]$} & {$[0.161,2.785]$} & {$[-0.230,2.136]$} \\
\hline Observations & 381 & 386 & 386 & 389 \\
\hline Bandwidth obs. & 210 & 217 & 268 & 265 \\
\hline Mean & 4.204 & 5.092 & 5.284 & 5.508 \\
\hline Effect size $(\%)$ & 13.34 & 3.83 & 27.08 & 16.09 \\
\hline Bandwidth & 0.075 & 0.076 & 0.108 & 0.105 \\
\hline (Local) polynomial order & 2 & 2 & 2 & 2 \\
\hline
\end{tabular}

Note: Local quadratic estimates of average treatment effects at cut-off estimated with triangular kernel weights and optimal MSE bandwidth. 95\% robust confidence intervals and robust p-values are computed following Calonico, Cattaneo and Titiunik (2014). Bandwidth obs. denotes number of observations in the optimal MSE bandwidth. The average value of contracts was transformed using inverse hyperbolic sine. The contracts are catalogued in each category by analysing their reported object. The Effect size (\%) is computed as the point estimate over the mean $\mathrm{x} 100 .{ }^{* * *} \mathrm{p}<0.01,{ }^{* *} \mathrm{p}<0.05,{ }^{*} \mathrm{p}<0.1$. 
Table A23: Donor funded politician and fire intensity by year of government Quadratic polynomial

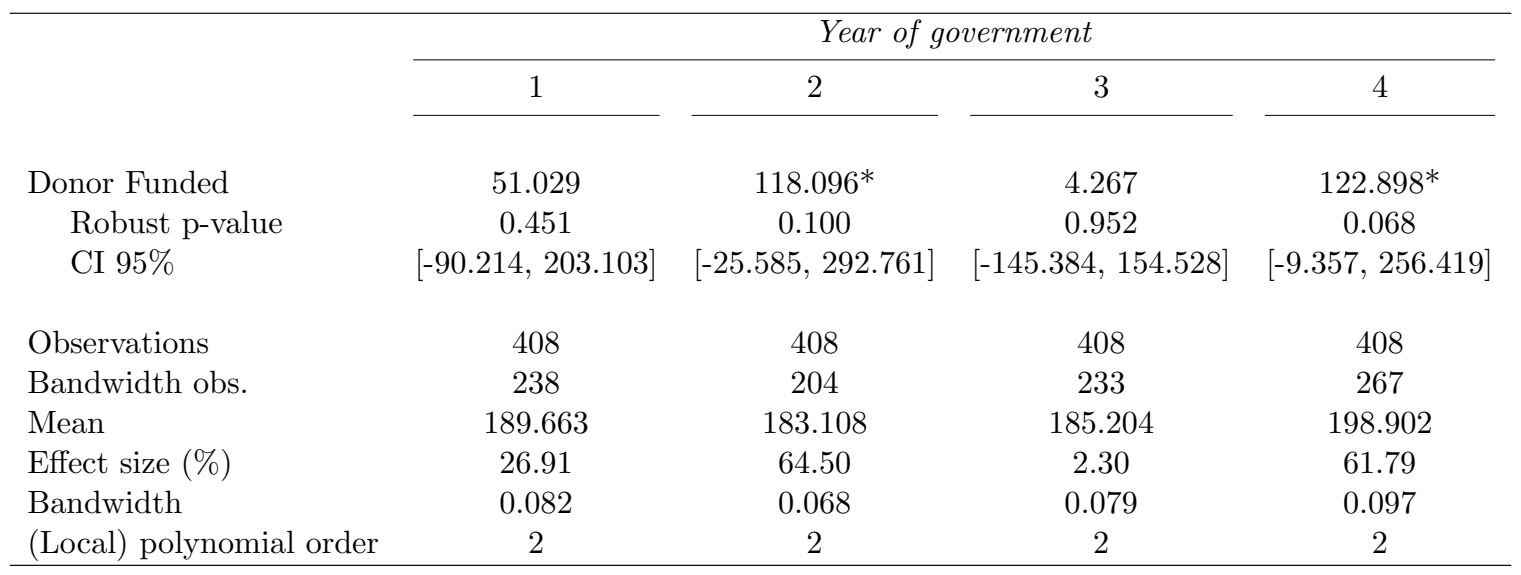

Note: Local quadratic estimates of average treatment effects at cut-off estimated with triangular kernel weights and optimal MSE bandwidth. 95\% robust confidence intervals and robust p-values are computed following Calonico, Cattaneo and Titiunik (2014). Bandwidth obs. denotes number of observations in the optimal MSE bandwidth. Fire intensity is measured as the average brightness of fires in a municipality. The Effect size (\%) is computed as the point estimate over the mean $\mathrm{x} 100$. $* * * \mathrm{p}<0.01,{ }^{*} \mathrm{p}<0.05, * \mathrm{p}<0.1$. 
Table A24: Heterogeneous effects: Guerrilla presence and ceasefire

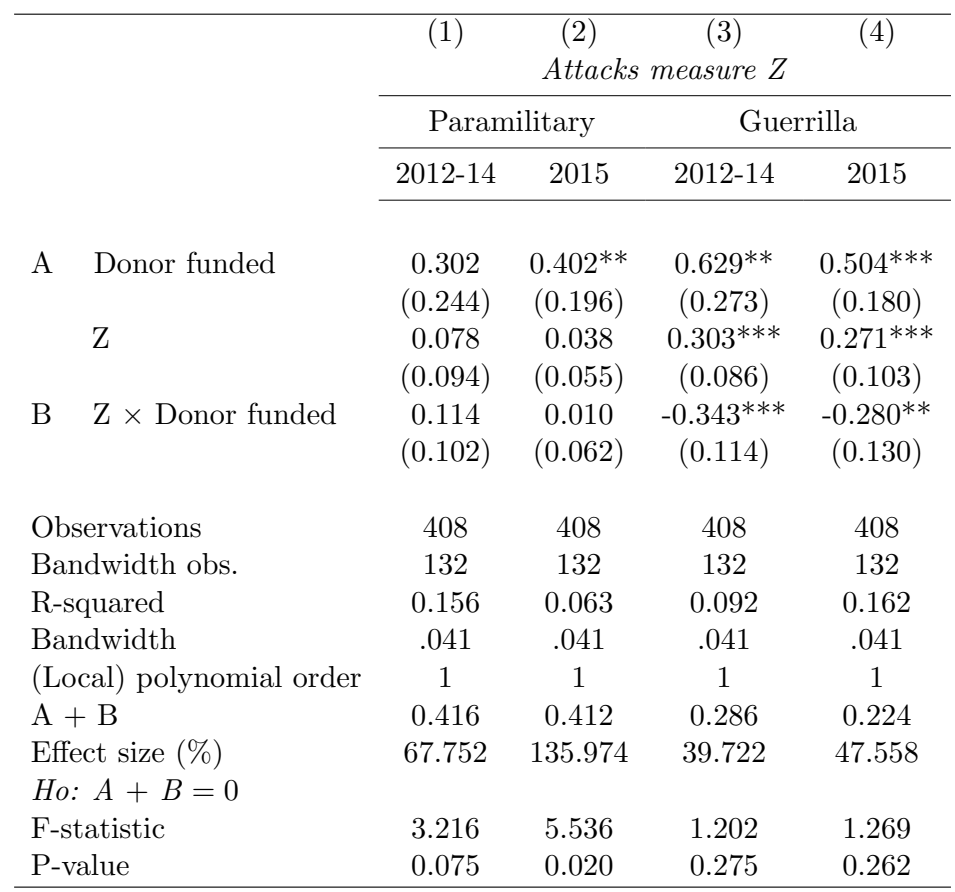

Note: OLS regression weighted by a triangular kernel within the MSE optimal bandwidth sample and controlling for a quadratic polynomial. The dependent variable is deforestation between 2012-2014 (columns 1 and 3) and deforestation in 2015 (columns 2 and 4). Bandwidth obs. denotes number of observations in the optimal MSE bandwidth. The dependent variable is deforestation during the full term. Paramilitary (Guerrilla) attacks is the number of paramilitary (guerrilla) attacks during the previous term (2008-2011). The Effect size (\%) is computed as $100 x(A+B) /\left(\right.$ constant $\left.+\beta_{Z}\right)$. *** $\mathrm{p}<0.01,{ }^{* *} \mathrm{p}<0.05,{ }^{*} \mathrm{p}<0.1$. 
Table A25: Descriptive statistics for donor-funded politicians

\begin{tabular}{lcc}
\hline Dependent variable & $\begin{array}{c}\text { Mean } \\
(1)\end{array}$ & $\begin{array}{c}\text { Std. Dev. } \\
(2)\end{array}$ \\
\hline & & \\
Total privately funded & 15.653 & 17.060 \\
Sh privately funded & 0.399 & 0.270 \\
Number of donors & 6.484 & 5.964 \\
Number of donations & 8.340 & 8.243 \\
& & \\
\hline
\end{tabular}

Note: There are a total of 408 Mayors in our base sample, 164 which are not donor-funded, while 244 are donor-funded. These descriptive statistics are for donor-funded politicians. "Total privately funded" is the total amount of private donations in millions of Colombian pesos. "Sh privately funded" is the \% of total campaign funds from private donations. 
Table A26: Private donations and deforestation: OLS

\begin{tabular}{|c|c|c|c|c|c|c|}
\hline & (1) & $(2)$ & $(3)$ & $(4)$ & $(5)$ & $(6)$ \\
\hline Share of private donations & $\begin{array}{c}0.862^{* *} \\
(0.350)\end{array}$ & $\begin{array}{c}0.590^{* *} \\
(0.298)\end{array}$ & & & & \\
\hline Number of private donations & & & $\begin{array}{c}0.017^{* *} \\
(0.007)\end{array}$ & $\begin{array}{c}0.007 \\
(0.006)\end{array}$ & & \\
\hline Number of private donors & & & & & $\begin{array}{c}0.029 * * * \\
(0.010)\end{array}$ & $\begin{array}{c}0.019 * * \\
(0.009)\end{array}$ \\
\hline Deforestation pre-term & & $\begin{array}{c}0.395 * * * \\
(0.042)\end{array}$ & & $\begin{array}{c}0.401^{* * *} \\
(0.044)\end{array}$ & & $\begin{array}{c}0.400^{* * *} * \\
(0.044)\end{array}$ \\
\hline Observations & 408 & 408 & 408 & 408 & 408 & 408 \\
\hline R-squared & 0.025 & 0.295 & 0.006 & 0.284 & 0.009 & 0.287 \\
\hline Mean DV & 1.210 & 1.210 & 1.210 & 1.210 & 1.210 & 1.210 \\
\hline
\end{tabular}

Note: This table presents an OLS regression for deforestation in the mayor's term. Share of private donations is the share of the mayor's electoral budget that privately funded and Number of private donations (private donors) is the number of private donations (donors) that the mayor received. Robust standard errors are presented in parenthesis. $* * * \mathrm{p}<0.01, * * \mathrm{p}<0.05,{ }^{*} \mathrm{p}<0.1$. 